\title{
Natural nuclei population dynamics in cavitation tunnels
}

\author{
M.T. Khoo • J.A. Venning • B.W. Pearce • K. Takahashi - T. Mori • \\ P.A. Brandner
}

Received: date / Accepted: date

\begin{abstract}
Nuclei, or microbubble, populations control the inception and dynamics of cavitation. It is therefore important to quantify distributions in cavitation test facilities to rigorously model nucleation dynamics. Measurements of natural nuclei population dynamics were made in two test facilities in Australia and Japan via mechanical activation using a Cavitation Susceptibility Meter (CSM). A range of tunnel operating parameters, including pressure, velocity and dissolved oxygen (DO) content, were investigated. The DO saturation condition upstream of the test section is found to provide a threshold as to whether the population is affected by DO in the Australian test facility. Historical trends in the population are quantified, indicating that regular monitoring is required. Variation of the population around the Australian cavitation tunnel circuit was studied by varying the water sampling location. Provided the water remains undersaturated, as defined above, the natural nuclei population in the test-section can be measured by sampling from the lower-limb resorber. Comparisons are made between test facilities in Australia, Japan and other countries, as well as environmental waters, using different measurement techniques. Optical and acoustic methods show microbubbles in the size range of 10 to $100 \mu \mathrm{m}$ typical of those used to
\end{abstract}

\section{M.T. Khoo}

Maritime Division

Defence Science and Technology Group

Fishermans Bend, Victoria, 3207, Australia

E-mail: matthew.khoo@dst.defence.gov.au

M.T. Khoo · J.A. Venning - B.W. Pearce · P.A. Brandner

Cavitation Research Laboratory

University of Tasmania, Australia

K. Takahashi · T. Mori

Naval Systems Research Center

Acquisition, Technology \& Logistics Agency, Japan model cavitation nucleation. CSM measurements show varying distributions of nuclei with equivalent bubble diameters in the range of 0.5 to $5 \mu \mathrm{m}$ but global trends suggest a universal characteristic.

Keywords Cavitation Susceptibility Meter · Nuclei measurement · Cavitation · Experimental techniques and facilities 
Graphic abstract

Cavitation Susceptibility Meter for measurement of nuclei population via mechanical activation

Piezoceramic sensor

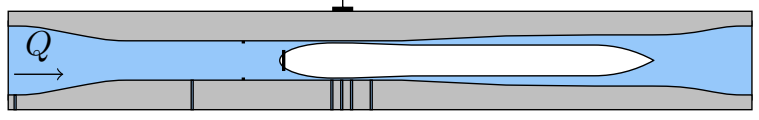

Pressure taps

1. Minimum throat pressure in centrebody venturi, $T_{\mathrm{c}}$, is known from calibration.

2. Nuclei concentration is derived from the nuclei activation and flow rates as $C=\frac{N}{\Delta t Q}$.
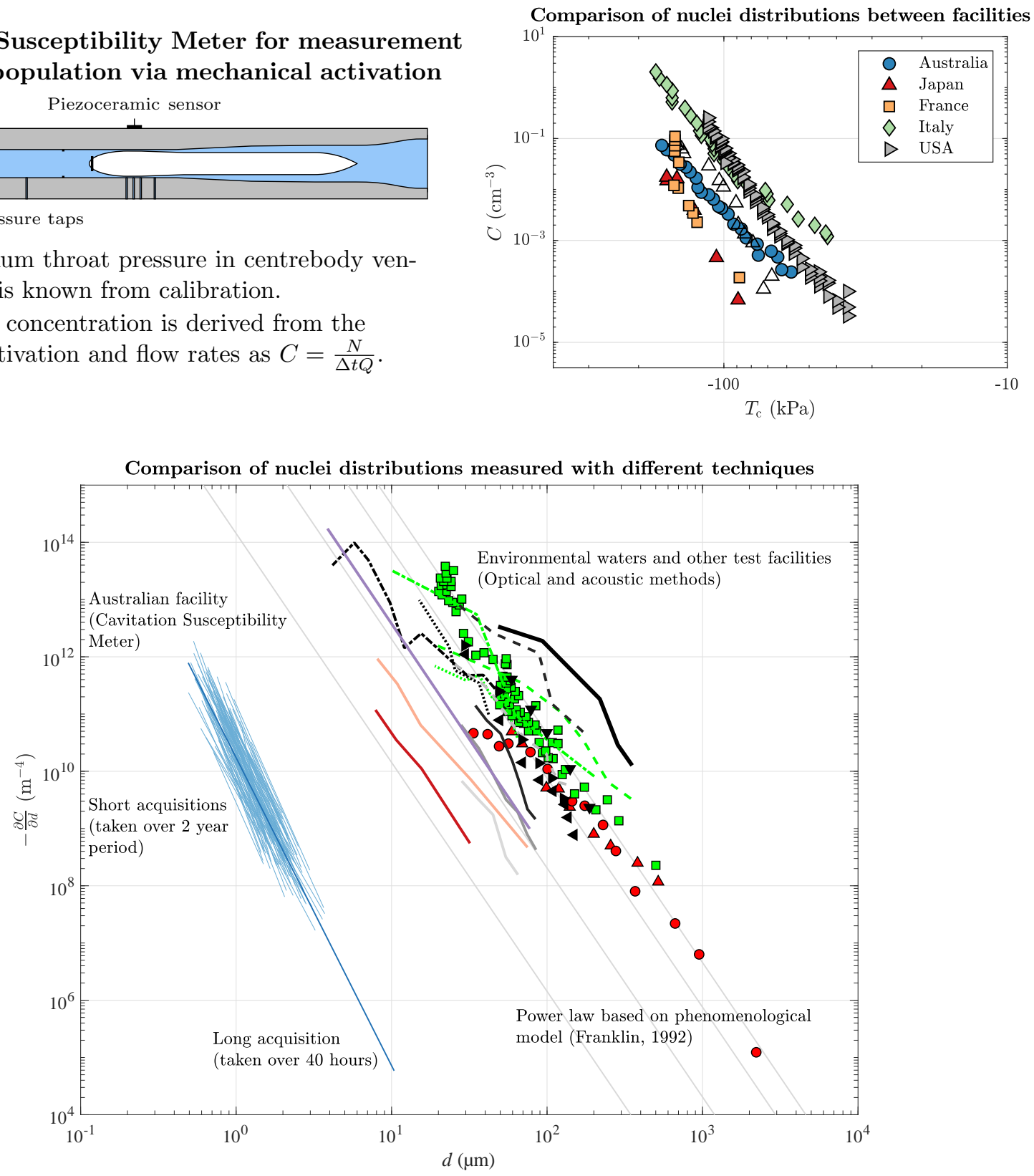


\section{Introduction}

Microbubble disperse flows are intrinsic to surface oceanography and naval hydrodynamics as they control, or interact with, many phenomena and processes of interest including cavitation inception and dynamics, gaseous diffusion, noise generation, acoustic and shockwave propagation and turbulence. With regard to cavitation, microbubbles provide nuclei that control the inception and dynamics of unsteady cavitation; but cavitation itself is also a prolific source of microbubbles by its very nature. Modelling of these flows experimentally remains a challenge as microbubble concentrations and size ranges may vary over several orders of magnitude. To this end, several techniques for generating and measuring microbubbles have been developed in the Cavitation Research Laboratory (CRL) at the Australian Maritime College (AMC) (Brandner, 2018). Sample results from these techniques for measuring microbubbles or nuclei populations in the AMC cavitation tunnel are shown in Fig. 1. Overall concentrations and sizes range over 10 and 5 orders of magnitude respectively. The population with the largest concentrations and sizes is typical of that in the wake of a cavitating object at relatively high Reynolds numbers (Russell et al., 2018). This population of relatively high concentration/larger microbubbles has been measured using Long-range Microscopic Shadowgraphy (LMS). The intermediate population is representative of a test flow artificially seeded with a relatively high concentration of microbubbles in the size range 10 to $100 \mu \mathrm{m}$ for experimental modelling of cavitation inception. These were measured using Interferometric Mie Imaging (IMI) (Brandner, 2018; Russell et al., 2019). The most sparse population shown in Fig. 1 is typical of the background or naturally occurring nuclei population ever present in the AMC cavitation tunnel under normal operating conditions. Optical measurement of these nuclei is impractical due to the low concentrations, requiring an excessive number of images. Furthermore, there is a diffraction limit on these techniques which constrains the smallest measurable bubble diameter to $\mathcal{O}(1) \mu \mathrm{m}$. The natural nuclei population has been measured via mechanical activation using a Cavitation Susceptibility Meter (CSM) (Khoo et al., 2017). It is the dynamics of this population within cavitation tunnels that is the subject of the present work.

Cavitation nucleation in practical flows is invariably heterogeneous. Such practical flows in test facilities and oceans contain dissolved gas and gas free as microbubbles that typically provide nuclei for cavitation inception. The equilibrium of a microbubble is unstable below a size-dependent critical pressure, $p_{\mathrm{c}}$. This can be

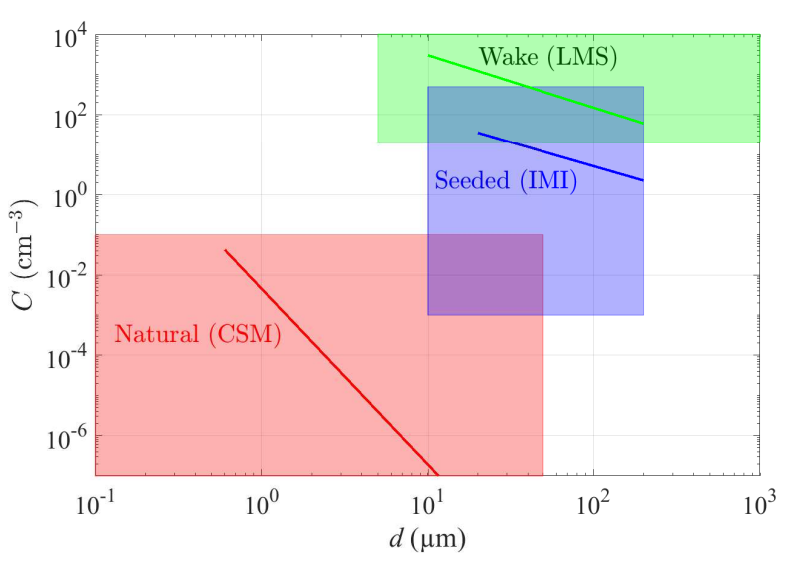

Fig. 1: Nuclei distribution graph showing the bubble diameter, $d$, and concentration, $C$, ranges (shaded regions) for which practical measurements can be made using the Cavitation Susceptibility Meter (CSM), Interferometric Mie Imaging (IMI) and Long-range Microscopic Shadowgraphy (LMS). Optical methods (e.g. IMI and LMS) are more suitable for higher concentrations of larger bubbles, while the hydrodynamic method (CSM) is suitable for lower concentrations of smaller bubbles. The lines represent recent nuclei measurements at the AMC cavitation tunnel.

expressed as a tension, $p_{\mathrm{c}}-p_{\mathrm{v}}$, where $p_{\mathrm{v}}$ is vapour pressure. The following equation gives this tension as a function of bubble diameter, $d$, and ambient pressure, $p_{\infty}$ :

$p_{\mathrm{c}}-p_{\mathrm{v}}=\frac{-2}{3 \sqrt{3}} \sqrt{\frac{(4 S / d)^{3}}{p_{\infty}-p_{\mathrm{v}}+4 S / d}}$

where $S$ is the surface tension. This can be derived from consideration of the equilibrium of bubble internal and external pressures and the surface tension assuming isothermal internal gas behaviour and no mass transfer via phase change or diffusion (Franc and Michel, 2006).

A bubble undergoes explosive growth once exposed to the critical pressure subsequently filling with vapour leading to rapid development of macroscopic cavitation. For microbubbles smaller than $100 \mu \mathrm{m}$ diameter, this critical pressure is well below vapour pressure, decreasing with decreasing size to several atmospheres of tension for micron-sized nuclei. That is, water may exist in a metastable state exposed to large tensions relative to vapour pressure before nucleation occurs. Vapour pressure represents a state of equilibrium, or more specifically dynamic equilibrium, between a liquid and its vapour and does not provide absolute limits on phase change.

Microbubble nucleation has been investigated extensively and remains a major area of research into the 
physics of cavitation inception and dynamics. Indeed, the literature is abundant with theoretical and experimental work on single bubble dynamics from which considerable insight has been gained and current understanding is largely based. However, there are other sources of cavitation nuclei in practical flows for which much less is known both in oceans, where there are organic and other impurities (Stramski et al., 2004), or test facilities where there may be less impurities. Venning et al. (2018) showed that the water in the AMC cavitation tunnel, where no microbubbles generated by cavitation or artificial nuclei seeding were present, is susceptible to cavitation at all tensions given sufficiently long sampling time. It was also observed that the relationship between concentration and critical tension is a power law. This is in line with observations made in various laboratory tests and in environmental waters.

Ocean surface bubble populations ranging from millimetre to micrometre scales have been studied extensively. Arguments for observed power-law relationships between concentration and size have been based on dimensional considerations (Garrett et al., 2000; Deane and Stokes, 2002). These involve larger bubble turbulent breakup limited by surface tension as expressed through the Hinze scale giving an index of $-10 / 3$ and for sub-Hinze scales where the production mechanism is jet entrainment with an associated index of $-3 / 2$. These indices may then be modified by the competing effects of buoyancy and dissolution. In a review of oceanography data by Zhang (2001) for bubble sizes ranging from order 10 microns to millimetre diameters, indices ranged from -7 to -2 although it was noted that -4 fits most results reasonably well. However, more recent near surface measurements have been made in Arctic ice leads showing similar global microbubble distributions in the absence of waves demonstrating that other mechanisms also produce such typical populations (Norris et al., 2011).

Similar results have been found for microbubble or nuclei populations in test facilities and environmental waters in a review by Billet (1985) citing an index of -3 . Gavrilov (1969) investigated microbubble populations in long standing tap water and reported an index of -3.5. Franklin (1992) argues that based on a powerlaw relationship between concentration and size and self similarity of the distribution that the index be -4 and further proposes a phenomenological theory for the concentration levels based on dissolved gas and molecular considerations that goes some way to explaining experimental results.

The gas within microbubbles will diffuse into the surrounding water if undersaturated with dissolved gas, resulting in complete dissolution of the bubbles. This is one of the mechanisms used in the AMC tunnel to continuously eliminate injected or cavitation generated microbubbles from the circuit. It has been postulated that nuclei may persist in cavitation tunnels due to gases trapped in crevices of hydrophobic particles (Harvey et al., 1944), bubbles being stabilised by a rigid permeable skin of organic impurities (Fox and Herzfeld, 1954) or surface contamination (Brennen, 1995) and from cosmic radiation (Brennen, 1995). Laboratory studies of ocean water by Johnson and Cooke (1981) show that bubbles created do dissolve but that there is a remnant population of stabilised microbubbles of sizes ranging from less than 1 to 13 microns. Observations have been made of nuclei distributions in cavitation test facilities, though detailed characterisations of the population dynamics are lacking in the literature. Nuclei content can be influenced by factors such as the hydrodynamic configuration and operating condition of the facility which affect the pressure history of the water (Gindroz et al., 1997; Atlar, 2002).

Natural nuclei concentrations and critical pressures have generally been observed to increase with decreasing pressure and velocity, as well as increasing relative saturation level of dissolved gas and tunnel operating history (Arndt and Keller, 1976; Liu et al., 1993; Brennen, 1994; Gindroz et al., 1997; Atlar, 2002; Nagaya et al., 2011). Other researchers have found that nuclei distributions do not change with pressure and velocity (Gates et al., 1979; Billet, 1984). However, this may be due to the limited range of test parameters investigated. For example, Billet (1984) mainly used relatively high test-section pressures and flow velocities. Although larger changes in nuclei content were observed with varying air content.

Due to the low concentration and low critical pressures of the natural nuclei population in the AMC tunnel they are not active in high cavitation number flows such as sheet and cloud cavitation (Venning et al., 2018). However, for low cavitation number flows where cavitation occurs in vortices such as shear layers, structured turbulence or tip vortices, it is vital that the natural population be measured to investigate inception and dynamics. In the present work, the operating parameters of the AMC cavitation tunnel are systematically varied in order to quantify their influence on natural nuclei populations. Venning et al. (2018) observed that the natural nuclei population in the AMC tunnel is invariant across normal operating conditions. In this study, the limits of this operating window are discussed, and further insights into the nature of the natural population are presented. Historical variations in the population are described. The natural nuclei pop- 
ulation dynamics in the AMC tunnel are compared with those in the Japanese Acquisition, Technology \& Logistics Agency (ATLA) Flow Noise Simulator (FNS), characterised using the same measurement equipment. Finally, natural nuclei distributions are compared across various test facilities and environmental waters using a range of nuclei measurement techniques.

\section{Experimental setup}

Nuclei measurements were acquired in the AMC cavitation tunnel and the ATLA FNS using the same AMC CSM. The main characteristics of each cavitation tunnel are provided in Tab. 1. Further details regarding the AMC and ATLA tunnel designs and operation are described in Brandner et al. (2007) and Mori et al. (2007) respectively. The experimental setup in each test facility is described below.

\subsection{AMC cavitation tunnel}

A schematic of the AMC cavitation tunnel is shown in Fig. 2. The variable-pressure, closed-circuit tunnel has a volume of $365 \mathrm{~m}^{3}$, with demineralised water the working fluid. The test section has a $0.6 \times 0.6 \mathrm{~m}$ cross section and is $2.6 \mathrm{~m}$ long. The test-section centreline absolute pressure can be varied between $4-400 \mathrm{kPa}$ and the nominal flow velocity range is $2-12 \mathrm{~m} / \mathrm{s}$.

The tunnel has ancilliaries for fast degassing and nuclei injection that enable strict control of the dissolved gas and nuclei contents. It also allows for continuous separation of bubbles that have been generated by cavitation or injected purposefully. This is achieved via a combination of gravity separation in a downstream tank and dissolution through extended residence in a resorber. The tunnel is designed to operate at low dissolved oxygen (DO) levels of nominally $30 \%$ of saturation at atmospheric pressure. This promotes microbubble dissolution around the entire circuit, but especially in the lower limb resorber with extended residence under high static pressure. The tunnel water spends about $50 \%$ of the total circulation time in the lower limb (39 s out of $85 \mathrm{~s}$ for a test-section velocity of $12 \mathrm{~m} / \mathrm{s}$ ). The natural nuclei population comprises any remaining nuclei. With the exception of one test to assess the effectiveness of free gas removal in the tunnel (Fig. 8), the nuclei injection system was not used for the present study. Similarly, no cavitating models generating microbubbles were present in the test section.

While the saturation conditions in the tunnel circuit are mostly undersaturated due to the extended residence and high static pressure in the lower limb, the

\begin{tabular}{|c|c|}
\hline AMC tunnel & ATLA tunnel \\
\hline \multicolumn{2}{|c|}{ Location } \\
\hline $\begin{array}{c}\text { Launceston, Tasmania, } \\
\text { Australia }\end{array}$ & $\begin{array}{l}\text { Nakameguro, Tokyo, } \\
\text { Japan }\end{array}$ \\
\hline \multicolumn{2}{|c|}{ Year established } \\
\hline 2011 & 2005 \\
\hline \multicolumn{2}{|c|}{ Material (wetted surfaces) } \\
\hline Stainless steel & Stainless steel \\
\hline \multicolumn{2}{|c|}{ Volume $\left(\mathrm{m}^{3}\right)$} \\
\hline 365 & 2000 \\
\hline \multicolumn{2}{|c|}{ Working fluid } \\
\hline Demineralised water & Filtered municipal water \\
\hline \multicolumn{2}{|c|}{ Test-section dimensions, $H \times W \times L(\mathrm{~m})$} \\
\hline $0.6 \times 0.6 \times 2.6$ & $2 \times 2 \times 10$ \\
\hline \multicolumn{2}{|c|}{ Test-section absolute pressure range (centreline) $(\mathrm{kPa}$} \\
\hline $4-400$ & $20-310$ \\
\hline \multicolumn{2}{|c|}{ Nominal test-section flow velocity range $(\mathrm{m} / \mathrm{s})$} \\
\hline $2-12$ & $1.5-15$ \\
\hline \multicolumn{2}{|c|}{ Test-section velocity profile uniformity } \\
\hline$<0.5 \%$ of mean velocity & $<1 \%$ of mean velocity \\
\hline \multicolumn{2}{|c|}{ Test-section turbulence intensity (\%) } \\
\hline$<0.5$ & $<0.5$ \\
\hline \multicolumn{2}{|c|}{ Main motor capacity $(\mathrm{kW})$} \\
\hline 200 & 2800 \\
\hline \multicolumn{2}{|c|}{ Microbubble seeding control } \\
\hline $\begin{array}{l}\text { Direct/dilute minitube } \\
\text { injector arrays with } \\
\text { downstream tank and } \\
\text { lower-limb resorber }\end{array}$ & $\begin{array}{l}\text { Single-point injection of } \\
\text { oversaturated water }\end{array}$ \\
\hline
\end{tabular}

Table 1: Specifications of the AMC and ATLA cavitation tunnels.

water can be exposed to oversaturated conditions in the test section through which the typical transit time is $\mathcal{O}(100) \mathrm{ms}$. This is also possible in the upper limb plenum upstream of test section for which the transit time is $\mathcal{O}(1)$ s. It will be shown later that there is a threshold saturation value in this part of the circuit below which the natural nuclei population is no longer independent of operating conditions.

\subsection{ATLA Flow Noise Simulator}

Comparative natural nuclei population measurements were made in a larger cavitation tunnel in Japan as part of a collaborative research project between ATLA and Australia's Defence Science and Technology Group. 


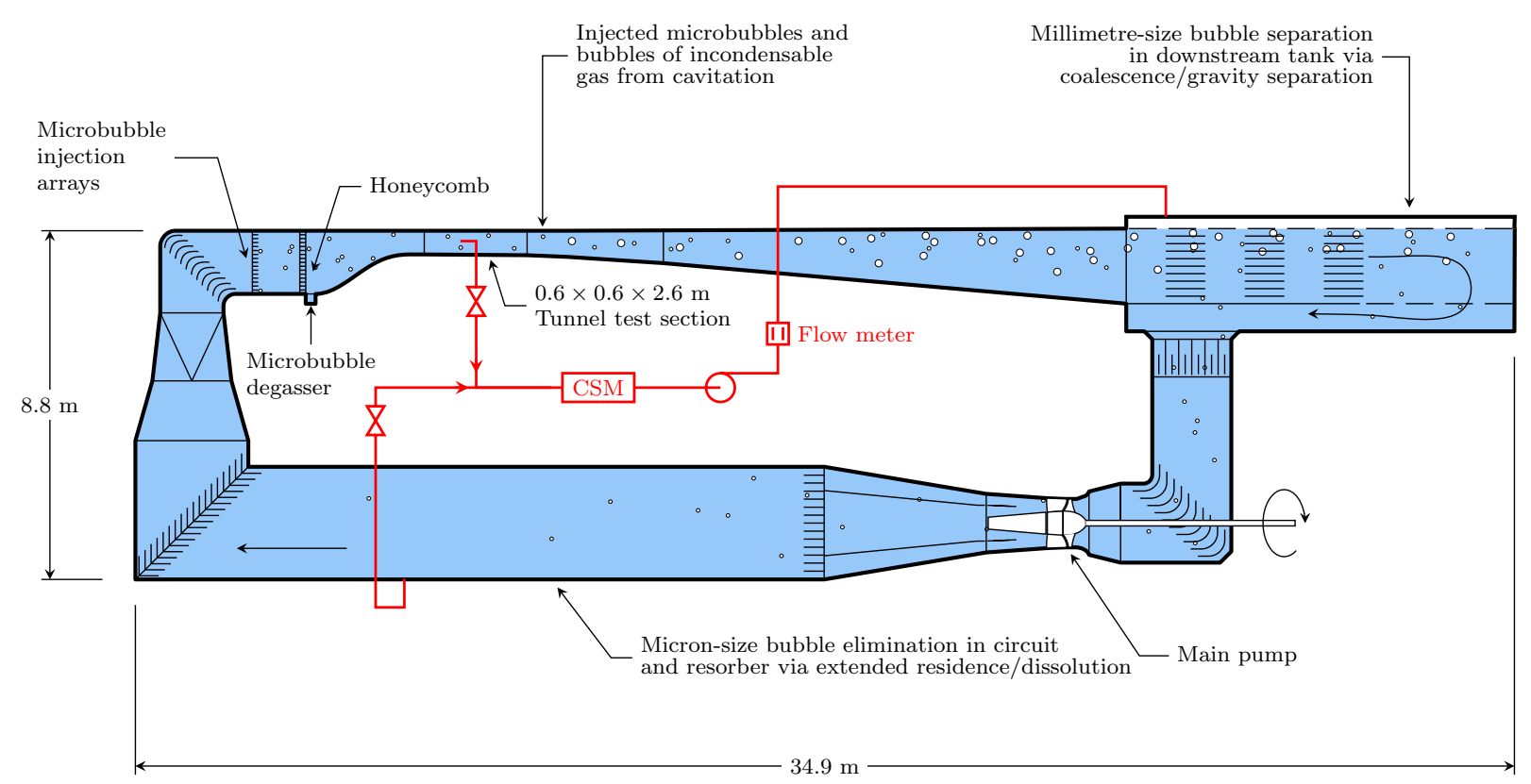

Fig. 2: Schematic of the AMC cavitation tunnel showing circuit architecture and ancillaries for microbubble and dissolved gas control and CSM circuit integration. Test water for the CSM can be sampled from either the tunnel test section or lower limb resorber.

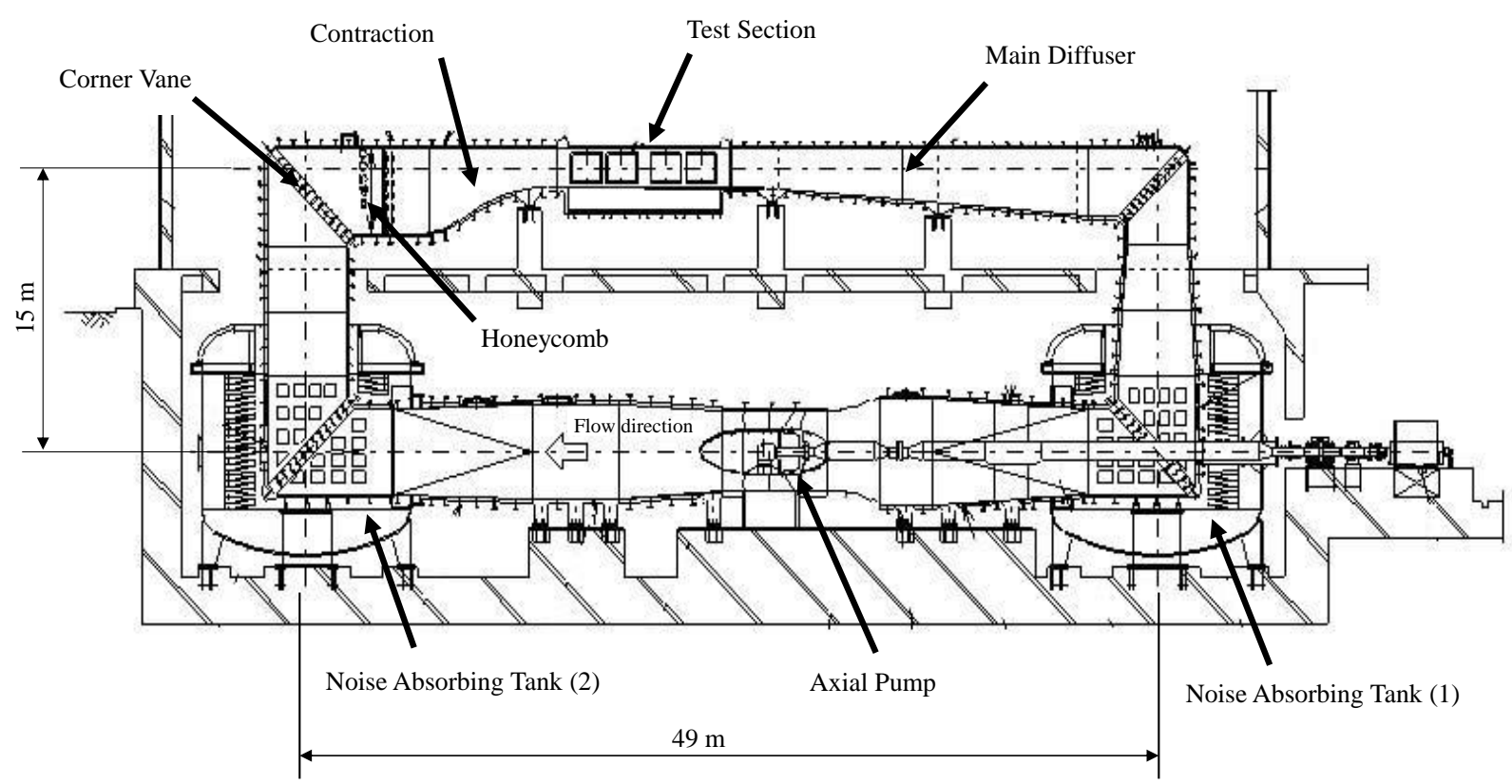

Fig. 3: Schematic of the ATLA Flow Noise Simulator. Test water for the CSM is sampled from the test section (not shown). 
The Japanese FNS is situated at ATLA's Naval Systems Research Center in Nakameguro, Tokyo, Japan (Fig. 3). The ATLA FNS test section has a $2 \times 2 \mathrm{~m}$ cross section and is $10 \mathrm{~m}$ long which makes it possible to study scaling effects on cavitation behaviour at large physical scales. It contains $2000 \mathrm{~m}^{3}$ of filtered municipal water and is operated over a range of DO contents, typically between $30 \%$ and $80 \%$ of saturation at atmospheric pressure. This is intended to reflect the varying conditions in which different marine vessels operate and to aid in the control of nuclei populations. The test-section centreline absolute pressure range is 20$310 \mathrm{kPa}$ and the flow velocity can be varied between $1.5-15 \mathrm{~m} / \mathrm{s}$. Water may spend a significantly longer duration exposed to oversaturated conditions in the FNS test section (1 to $2.5 \mathrm{~s}$ ) compared to that in the AMC tunnel. This suggests that the saturation conditions in the ATLA FNS test section, by virtue of its larger size, play a more significant role in controlling the natural nuclei population compared to the AMC facility. This observation is supported by the results presented later. The differences in operating conditions and circuit architecture between the AMC and ATLA tunnels represent alternative strategies for nuclei management and control. For the ATLA tunnel, nuclei control is principally achieved through variation of dissolved gas.

\subsection{AMC cavitation susceptibility meter}

The AMC CSM (Fig. 4) was designed by YLec Consultants (Grenoble, France) and is also known as the 'Venturix' (Pham et al., 1997). It is a hydrodynamic device that uses a centrebody venturi to reduce the pressure and thus activate nuclei in the flow. A piezoceramic sensor bonded to the external sleeve around the venturi is used to detect nuclei activations and ultrasonic flow meters are used to measure the flow rate. The combined measurement of activation rate and volumetric flow rate for a series of throat pressures provides a cumulative distribution of concentration against critical tension.

The tension applied to the water in the venturi is derived from a calibration based on the flow rate through the venturi and prior measurement of the pressure at four streamwise locations along the outer sleeve of the centrebody venturi. This tension represents the critical pressure of the strongest nucleus activated in the venturi. Sample calibration measurements are given in Fig. 4 for two Reynolds numbers $\left(R e=\frac{U D}{\nu}\right.$, where $U$ is the mean flow velocity, $D$ is the pipe diameter and $\nu$ is the fluid kinematic viscosity). The data are represented as pressure coefficients $\left(C_{\mathrm{p}}=\frac{p_{\mathrm{x}}-p_{1}}{\frac{1}{2} \rho U^{2}}\right.$, where $p_{\mathrm{x}}$ is the pressure at location $x$ in the throat, $p_{1}$ is the pressure at a reference location upstream of the venturi and $\rho$ is the density of water). At the higher Reynolds number, the boundary layers are thinner, increasing the effective cross-sectional area of the venturi, and thus the pressure drop is reduced. The solution for one-dimensional inviscid theory demonstrating the upper bound with Reynolds number is shown for reference. The calibration thus characterises how the pressure coefficient in the venturi changes with Reynolds number. More detailed information on the calibration of the CSM is described in Khoo et al. (2016).

Cavitation events are counted by measuring the voltage, $V_{\mathrm{P}}$, across a piezoceramic sensor $(1 \mathrm{MHz}$ resonant frequency). The signal is sampled at $2 \mathrm{MHz}$. A four stage discriminator algorithm is used to count individual nuclei activations:

1. High-pass filter (to remove low frequency structural resonance)

2. Rectification (to make all events the same sign)

3. Low-pass filter (to smooth response to activations into single peaks)

4. Log function (to homogenise response amplitudes to improve peak discrimination)

An example of raw and processed signals is shown in Fig. 5. The effect of discriminator threshold level on the total nuclei count is shown in Fig. 6, for the complete dataset from which the results shown in Fig. 5 were extracted. If the threshold is set too high, nuclei events are missed. Conversely, if the threshold level is set too low, additional peaks due to unfiltered structural response
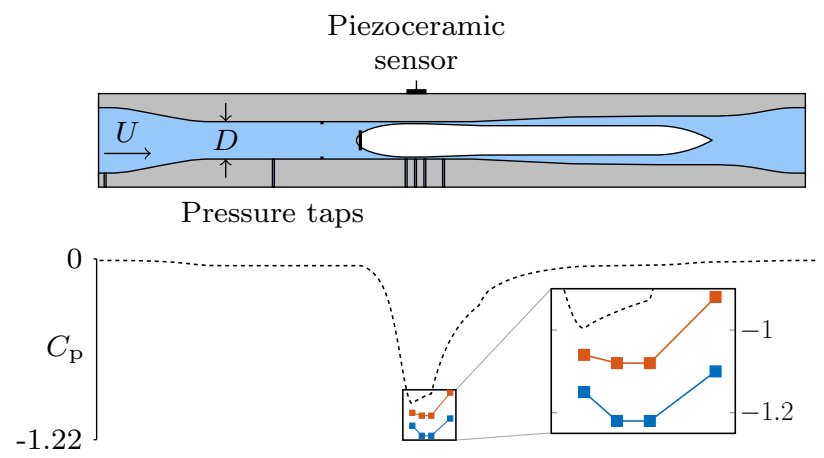

Fig. 4: Schematic showing venturi arrangement and location of sensor and pressure taps. The centrebody is shown in white and outer sleeve in grey. Bottom plot is pressure coefficient, $C_{\mathrm{p}}$, against location (scaled to the schematic) showing the measured pressure coefficient (squares) for the minimum $\left(2.9 \times 10^{4}\right.$, blue $)$ and maximum $\left(1.5 \times 10^{5}\right.$, red) Reynolds numbers and the solution from one-dimensional inviscid theory in black dashes. 
are counted, resulting in a higher nuclei concentration. The threshold has been set to discriminate all peaks on the time series which corresponds with a plateau shown in Fig. 6.
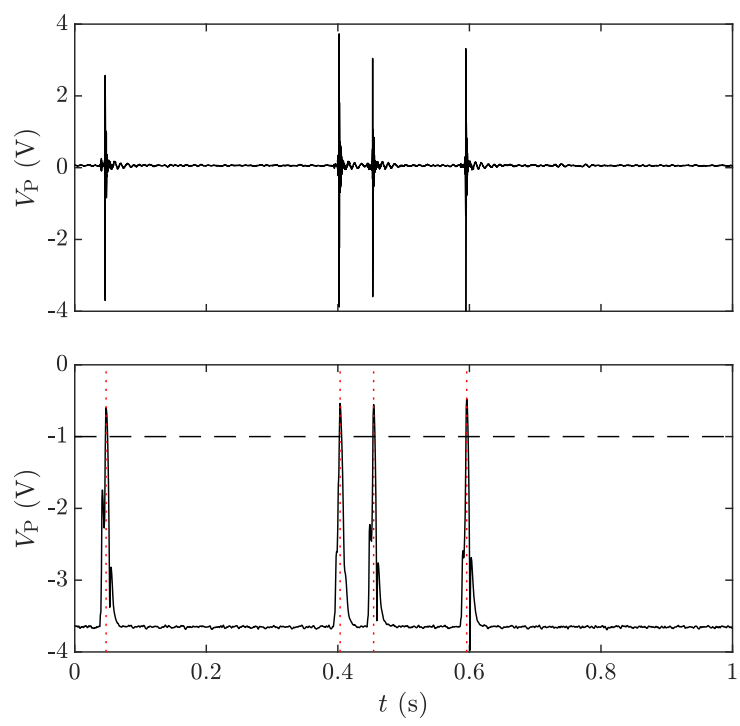

Fig. 5: Voltage output, $V_{\mathrm{P}}$, from CSM piezoceramic sensor: raw (top) and processed (bottom). A threshold level of -1 (horizontal, dashed line) gives a count of 4 . Vertical, dotted lines indicate detections.

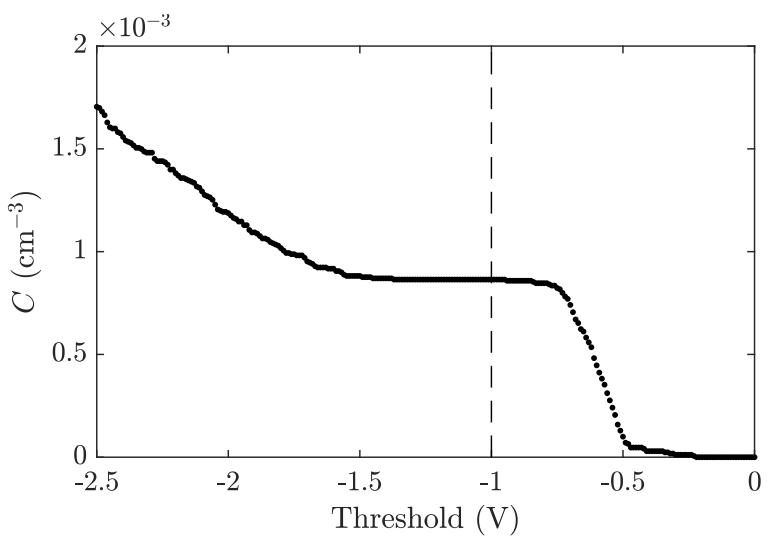

Fig. 6: Effect of CSM discriminator threshold setting on measured nuclei concentration, $C$.

The CSM is suitable for measuring nuclei with critical pressures ranging to several atmospheres of tension corresponding to micro- and nanometre equivalent bubble sizes, in hydrodynamic test facilities. A particular advantage of the CSM for nuclei measurements is that critical pressures of all viable nuclei that would be ac- tive in a cavitating flow are directly measured. This is in contrast with optical techniques where all entities (e.g. microbubbles and particles) are measured whether they are viable nuclei or not. Although critical pressures can be estimated for microbubbles measured optically, this is not possible for active particles which can only be measured by mechanical activation. Optical techniques are also limited in minimum measurable sizes by the diffraction limit of the system.

A shortcoming of mechanical activation techniques is that although larger microbubbles greater than about $50 \mu \mathrm{m}$ in diameter are counted, their size cannot be determined with high accuracy as critical pressures are all close to vapour pressure. As water must be sampled for this technique, it can be intrusive and has no spatial resolution which therefore makes it only suitable for measurements of natural nuclei populations. The maximum concentration measurable with the present AMC CSM is approximately $0.3 \mathrm{~cm}^{-3}$ before either the CSM venturi throat, or the discriminator algorithm, become saturated. Dilution of the sampled water may be used to reduce the cavitation event rate, but this may also alter the nuclei population.

In both test facilities, water was sampled from the test section through a streamlined sampling probe designed to avoid cavitation across the typical range of tunnel operating conditions. In the AMC cavitation tunnel, the probe was mounted to the test-section floor, nominally midway along the test section, with water sampled from the test section centreline. In the ATLA FNS, the probe was mounted to the test-section side wall, located about $8 \mathrm{~m}$ from the test-section entrance, $1 \mathrm{~m}$ from the ceiling, with water sampled $0.3 \mathrm{~m}$ away from the wall. Water was passed through the venturi located approximately $5 \mathrm{~m}$ below the test section. The length of pipework between the sampling probe and venturi was about $7 \mathrm{~m}$ for the AMC cavitation tunnel and about $13 \mathrm{~m}$ for the ATLA FNS, resulting in about twice the transit time at the ATLA tunnel. In the AMC tunnel, water can alternatively be sampled from the resorber in the lower limb of the tunnel. This has implications for measurement of natural nuclei populations during cavitation testing, as discussed later in Sect. 3.5.

The natural nuclei population in the ATLA tunnel is known to be strongly dependent on tunnel operating history (Takahashi et al., 2019). Therefore, the same pre-pressurisation procedure was used prior to each nuclei distribution measurement to minimise these effects. The FNS test-section pressure was set to $200 \mathrm{kPa}$ for at least 10 minutes, then reduced to the value specified for the nuclei measurement. After the test-section conditions were set in either facility (i.e. pressure, $p_{\mathrm{TS}}$, flow 
velocity, $U_{\mathrm{TS}}$, and DO concentration, $c$ ), the venturi throat pressure was set using a downstream pump to produce approximately one cavitation event every $10 \mathrm{~s}$. The throat pressure was systematically decreased by incrementally increasing the pump speed and data were recorded at each pressure. This process was repeated until a flow rate was reached such that the throat pressure could no longer be reduced (choked condition) or the event rate saturates being too high for individual events to be discriminated (>300 events per second).

\subsection{Data reduction and presentation}

The nuclei populations reported in this paper, with the exception of Fig. 23, are cumulative distributions representing the concentration of nuclei in the sampled volume of water that have a critical pressure, $p_{\mathrm{c}}$, equal to or greater than the minimum venturi throat pressure at that measurement point. The critical pressure is typically expressed as a tension, $T_{\mathrm{c}}=p_{\mathrm{c}}-p_{\mathrm{v}}$, which represents how much the throat pressure, $p_{\mathrm{c}}$, must be reduced below vapour pressure, $p_{\mathrm{v}}$, for a nucleus to be activated.

The DO concentration is measured in units of $\mathrm{mg} / \mathrm{L}$ and can be expressed as a percentage, $\gamma$, which describes the ratio of the DO concentration at a given pressure to saturation at atmospheric pressure $(9.1 \mathrm{mg} / \mathrm{L}$ at $20^{\circ} \mathrm{C}$ ). The saturation level of DO in water at equilibrium conditions, $c_{\text {sat }}$, at a given pressure and temperature can be calculated using the following equations (Warneck and Williams, 2012; Worch, 2015):

$c_{\mathrm{sat}}=p_{\mathrm{g}} K_{\mathrm{H}} M$

where $p_{\mathrm{g}}=0.21\left(p_{\infty}-p_{\mathrm{v}}\right)$ is the partial pressure of oxygen in air saturated with water vapour, $p_{\infty}$ is the ambient pressure of the water, $K_{\mathrm{H}}$ is the Henry's law constant and $M$ is the molar mass $\left(32 \mathrm{~g} / \mathrm{mol}\right.$ for $\left.\mathrm{O}_{2}\right)$.

It is also useful to calculate the saturation pressure, $p_{\text {sat }}$, corresponding to a particular measured dissolved oxygen concentration, $c$ :

$p_{\mathrm{sat}}=p_{\mathrm{v}}+\frac{c}{0.21 K_{\mathrm{H}} M}$

The relative saturation level of oxygen in water, $r$, which describes the tendency for DO to either pass into solution, or come out of solution as free gas, is defined as the ratio of the measured DO concentration and the saturation level of DO at a reference pressure, $p_{\infty}$ :

$r=\frac{c}{c_{\mathrm{sat}}} \times 100 \%$

That is, ignoring surface tension, if $r>100 \%$ the water is oversaturated and dissolved gas will tend to be released and for $r<100 \%$ the water will be undersaturated and gas will tend to pass into solution. As an example, the saturated DO concentration in water at $20^{\circ} \mathrm{C}$ and an ambient pressure of $35 \mathrm{kPa}$ is $c_{\text {sat }}=$ $3 \mathrm{mg} / \mathrm{L}$. If the measured DO concentration in the water is $c=2.4 \mathrm{mg} / \mathrm{L}$, the relative saturation is $r=80 \%$ and therefore the water is undersaturated. Given an air-water interface, oxygen would dissolve in the water at this condition. Since the pressure varies throughout the circuit and changes with test-section conditions, the degree of saturation varies accordingly. For the AMC tunnel, a suitable reference pressure is that within the plenum upstream of the contraction, $p_{\text {up }}$. The reasoning for this is that the water spends about 20 times longer in the plenum $(\mathcal{O}(1) \mathrm{s})$ compared to the test section $(\mathcal{O}(100) \mathrm{ms})$, so the saturation conditions in this part of the circuit influence gas exchange or transport between liquid and free gas bubbles much more than the test-section conditions. The notation for the relative saturation is therefore $r_{\text {up }}\left(r_{\mathrm{TS}}\right.$ is used when testsection pressure is the reference pressure). The pressure in the plenum is given by:

$p_{\mathrm{up}}=p_{\mathrm{TS}}+\frac{1}{2} \rho U_{\mathrm{TS}}^{2}\left(1-\eta^{2}\right)-\rho g h$

where $\rho$ is the density of water, and for the AMC cavitation tunnel, $\eta=\frac{9}{64}$ is the contraction ratio and $h=-0.5 \mathrm{~m}$ is the height of the centreline upstream of the contraction relative to the test-section centreline. For the ATLA FNS, $\eta=\frac{1}{5.06}$ and $h=-1.25 \mathrm{~m}$. However, water spends $\mathcal{O}(1) \mathrm{s}$ in the ATLA FNS test section and it is therefore expected to play a more significant role in controlling the natural nuclei population.

\section{Results}

\subsection{Convergence study}

A convergence study was undertaken at a number of venturi throat tensions to identify a suitable sampling duration. Typical tunnel operating conditions for cavitation studies were used $\left(p_{\mathrm{TS}}=50 \mathrm{kPa}, U_{\mathrm{TS}}=7 \mathrm{~m} / \mathrm{s}\right.$ and $\gamma=38 \%$ ). Figure 7 shows a comparison of data taken in 60 and $600 \mathrm{~s}$ blocks. The amount of scatter increases as the magnitude of the tension decreases due to the decreasing nuclei activation rate, and thus smaller sample sizes for a given sampling duration. This scatter could be reduced by using an event count criterion (rather than a fixed acquisition time) to increase the sample size for throat pressures closer to vapour pressure, as used by Venning et al. (2018). However, the long acquisition durations required to capture large sample sizes at such throat tensions can become impractical 
when multiple measurements are required. Assuming that the data for the 10 minute runs have converged, $60 \mathrm{~s}$ blocks were deemed to be acceptable as they give sufficient convergence for the purposes of this study while minimising total data acquisition time. It should be noted that a more conservative sampling duration of $120 \mathrm{~s}$ was used at the ATLA FNS.

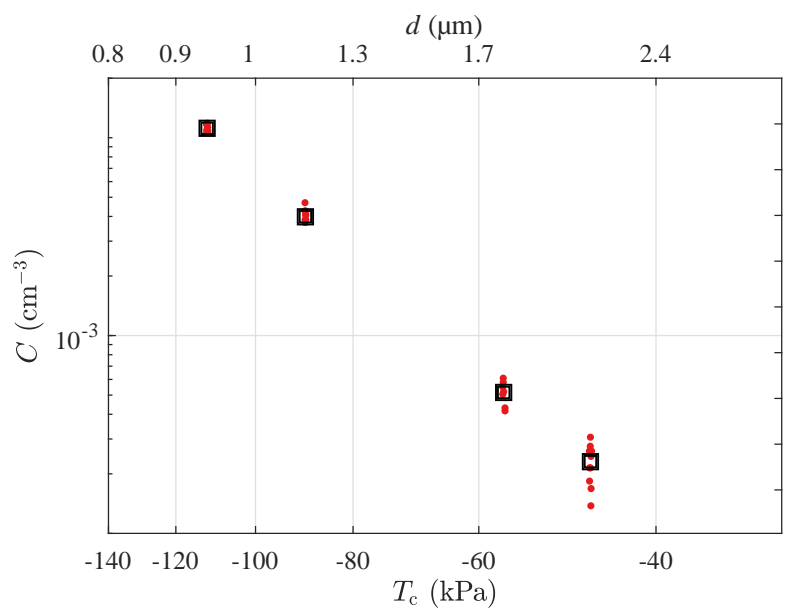

Fig. 7: Cumulative nuclei distribution as nuclei concentration, $C$, against critical tension, $T_{\mathrm{c}}$. The corresponding equivalent bubble diameters, $d$, are also provided. The squares and red points represent 600 and 60 second acquisition periods (or blocks), respectively. Tunnel conditions were $p_{\mathrm{TS}}=50 \mathrm{kPa}, U_{\mathrm{TS}}=7 \mathrm{~m} / \mathrm{s}$ and $\gamma=38 \%$.

\subsection{Effectiveness of free gas removal}

A test was conducted to assess the effectiveness of free gas removal in the test facility. The measured nuclei concentration for a constant venturi throat pressure, $T_{\mathrm{c}}=-14 \mathrm{kPa}$, is shown in Fig. 8. The nuclei injection system was turned on at the first vertical line and off at the second then the time taken for the concentration to stabilise or return to its initial state was observed. The results show that the measured nuclei concentration increased within $10 \mathrm{~s}$ after nuclei injection was started and returned to its initial state within $20 \mathrm{~s}$ after injection was halted. As bubble dissolution in the CSM circuit is possible (Gowing et al., 1988), further microbubble measurements were made in the test section using IMI (Brandner et al., 2018). The results showed the same behaviour as for the CSM, confirming that free gas is effectively removed from the AMC tunnel and that injected nuclei do not recirculate and accumulate, at least for typical tunnel operating conditions.

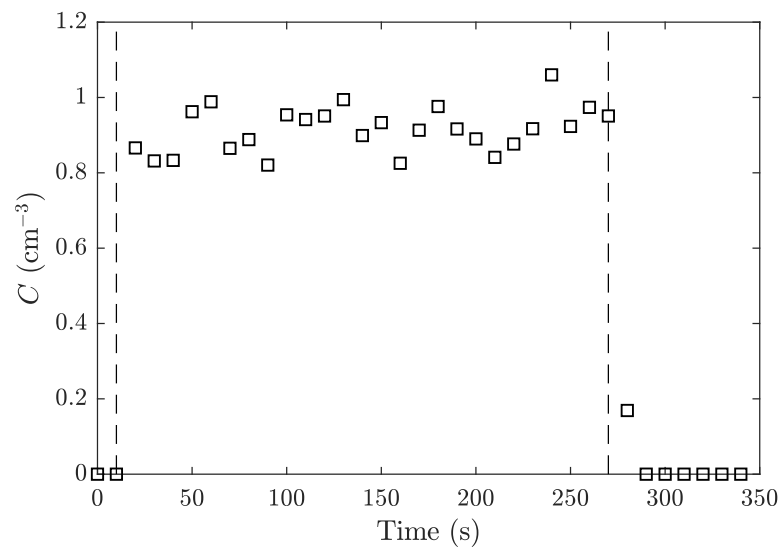

Fig. 8: Effectiveness of free gas removal in the AMC cavitation tunnel. The nuclei concentration, $C$, is seen to increase immediately after start of injection (left, dashed line) then to return back to the initial level shortly after injection is ceased (right, dashed line). Tunnel conditions were $p_{\mathrm{TS}}=50 \mathrm{kPa}, U_{\mathrm{TS}}=7 \mathrm{~m} / \mathrm{s}$ and $\gamma=32 \%$. Venturi throat pressure was $T_{\mathrm{c}}=-14 \mathrm{kPa}$ (equivalent bubble diameter of $d=5.8 \mu \mathrm{m}$ ).

\subsection{Historical trends}

Variations in the natural nuclei population over time in the AMC tunnel were recorded using continuous CSM measurements at a fixed throat tension $\left(T_{\mathrm{c}}=-80 \mathrm{kPa}\right)$ and undersaturated test-section conditions over 35 hours with tunnel operating conditions of $p_{\mathrm{TS}}=50 \mathrm{kPa}$ and $U_{\mathrm{TS}}=7 \mathrm{~m} / \mathrm{s}$. The nuclei concentration for this tension gradually decreases by approximately $1.8 \times 10^{-3} \mathrm{~cm}^{-3}$ during this period, as shown in Fig. 9. The same y-axis range is used as for later graphs (e.g. Fig. 11) which allows the changes to be assessed relative to the other nuclei distribution measurements. Note that the DO content increased from $37 \%$ to $51 \%$ over the 35 hours due to equilibration, which includes air dissolution via the free surface in the upper part of the tunnel downstream tank. There are several possible explanations for the decrease in concentration, including depletion of nuclei due to activation and destruction during the CSM measurement process, long term exposure to undersaturated conditions and natural variations in the potential populations of gas-containing microorganisms.

Calculations were carried out to assess the viability of the depletion hypothesis. Knowing the nuclei activation rate in the CSM and flow rate through the device, the total number of activations over the 35-hour period is estimated as $1.6 \times 10^{5}$. If the overall population had decreased by this amount, the concentration would have reduced to $2.0 \times 10^{-3} \mathrm{~cm}^{-3}$, which is higher than the final measured concentration of about $0.57 \times 10^{-3} \mathrm{~cm}^{-3}$ 


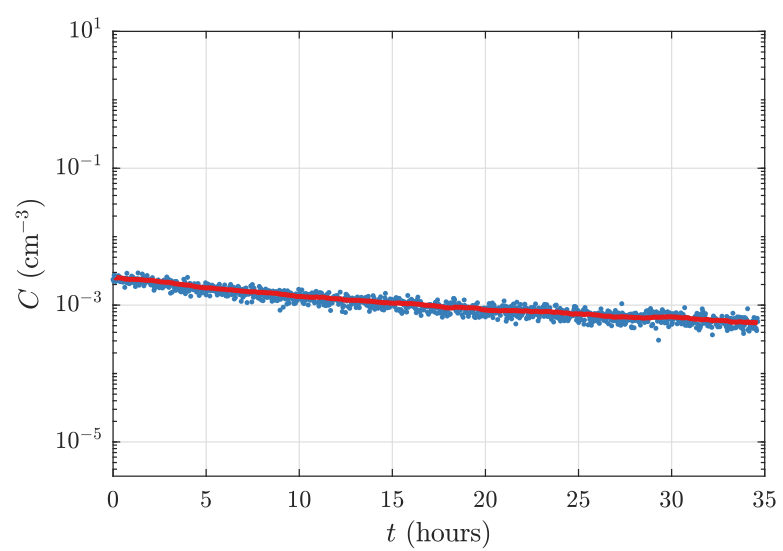

Fig. 9: CSM measurements showing a reduction in natural nuclei concentration in water subjected to a tension of $T_{\mathrm{c}}=-80 \mathrm{kPa}$ (equivalent bubble diameter of $d=1.3 \mathrm{\mu m}$ ) over a 35 hour period. The blue data points represent sequential acquisitions in $100 \mathrm{~s}$ blocks. The red line is a moving average of these data. Tunnel conditions were $\gamma=39 \%(t=0 \mathrm{~h}) \rightarrow 53 \%(t=35 \mathrm{~h})$, $p_{\mathrm{TS}}=50 \mathrm{kPa}$ and $U_{\mathrm{TS}}=7 \mathrm{~m} / \mathrm{s}$.

That is, the number of activations would only account for about $23 \%$ of the observed reduction in concentration. This suggests that nuclei depletion due to CSM operation is not the major or sole contributor to the observed reduction in nuclei concentration with time.

Historical trends were further studied by taking daily measurements of the natural nuclei population at the same nominal tunnel conditions (undersaturated in the test section and plenum) during a one-week test campaign. These data presented in Fig. 10 show the population to shift to the lower left over the week. This corresponds to a reduction in cumulative concentration of about an order of magnitude for a fixed tension. It is difficult to ascertain whether it is the concentration or tension, or both, that is varying with time. After several weeks of other experiments, the undersaturated natural nuclei population was remeasured and observed to return to close to its initial position. Similar regeneration has also been observed after degassing using bubble injection. Furthermore, monitoring over a two-year period has shown the natural nuclei population to fluctuate within an order of magnitude, which indicates that although there is no single baseline population, there do appear to be upper and lower bounds.

As noted above, the natural nuclei population is potentially affected by several properties of the water or processes within the tunnel including gaseous diffusion between tunnel water and the gas volume used to control the tunnel pressure, diffusion between nuclei and tunnel water around the circuit driven by pressure and residence variations, although the former has been developed to be a relatively slow process. Other possible influences are contaminants of various origins and even cosmic radiation. Given the complexity of such a system it is difficult to gain more understanding from the current investigation. Clearly, further insights must be gained from systematic elimination of these factors including testing with a much smaller isolated volume of water eliminating mass transfer, fixing the volume of dissolved gas, treatment to set or control contaminants including sterilisation to eliminate any biological entities, minimising pressure variations and shielding from radiation. In such a setup the natural nuclei population could be continuously measured with a CSM providing the opportunity to assess its dynamic behaviour with greater control over the properties and processes which may affect natural nuclei over time.

Without an accurate measurement or prediction of the nuclei content, unexplained differences in cavitation inception results could occur from day to day. Ideally, the natural nuclei population could be predicted using a database or model based on tunnel conditions such as test-section pressure, velocity and DO content. However, the observed historical trends, which are not currently well-understood, preclude the use of a modelbased approach. Until these factors are better understood, regular monitoring of the natural nuclei population is necessary when investigating cavitation phenomena that are influenced by nuclei content.

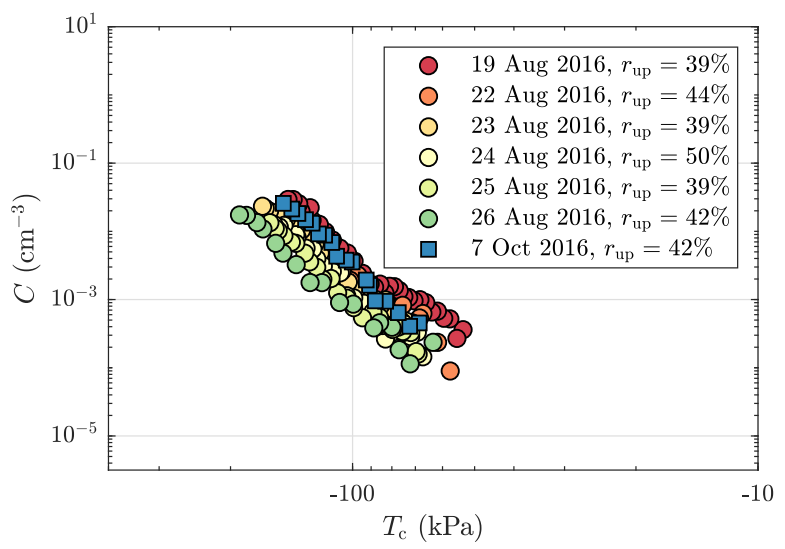

Fig. 10: CSM measurements over a one-week test campaign (circles) showing a reduction in natural nuclei population, then regeneration after several weeks (squares). Note that the tunnel conditions were varied in between measurements, but each nuclei distribution was measured at the same nominal conditions of $\gamma=30-39 \%, p_{\mathrm{TS}}=50 \mathrm{kPa}$ and $U_{\mathrm{TS}}=7 \mathrm{~m} / \mathrm{s}$. 


\subsection{Effect of test-section conditions}

The effect of test-section pressure on the natural nuclei population is presented in Fig. 11, for a low DO content and a mid-range test-section flow velocity. No significant differences between the measured distributions are evident over the range of pressures tested, with the exception of a slight reduction in concentration for the highest test-section pressure. The distributions in Fig. 11 appear to follow a power law, consistent with the findings of Venning et al. (2018). Uncertainty bars are also provided in Fig. 11 for one of the data series. Further details on this uncertainty analysis can be found in Khoo et al. (2016).

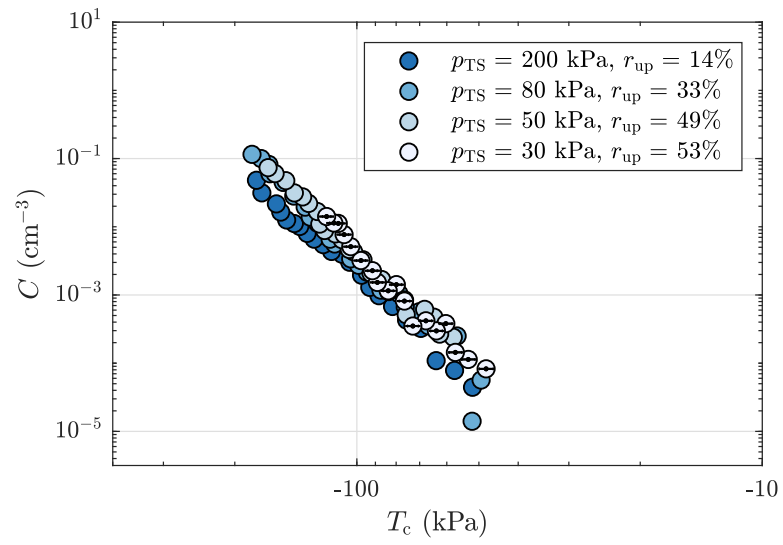

Fig. 11: Effect of test-section pressure, $p_{\mathrm{TS}}$, on the natural nuclei population. The relative saturation level of oxygen in the plenum, $r_{\text {up }}$, is also provided. Test-section pressure has little influence across this range of tunnel conditions. Uncertainty intervals for both tension and nuclei concentration are plotted for the $30 \mathrm{kPa}$ data series. Tunnel conditions were $\gamma=30-38 \%$ and $U_{\mathrm{TS}}=7 \mathrm{~m} / \mathrm{s}$.

The effects of test-section flow velocity and DO content on the natural nuclei population are shown in Figs. 12 and 13, respectively. Over this range of conditions, neither parameter has a measurable influence. This indicates that for typical operating conditions, the natural nuclei population is independent of the AMC cavitation tunnel conditions. The nuclei distributions presented thus far were measured under conditions for which the water in the plenum was undersaturated $\left(r_{\text {up }}<100 \%\right)$. That is, the static pressure in the plenum was greater than the equilibrium saturation pressure, meaning that free oxygen will tend to dissolve in the water.

In contrast, at extreme operating conditions, higher concentrations of weaker nuclei were observed when the sampled water was exposed to oversaturated conditions

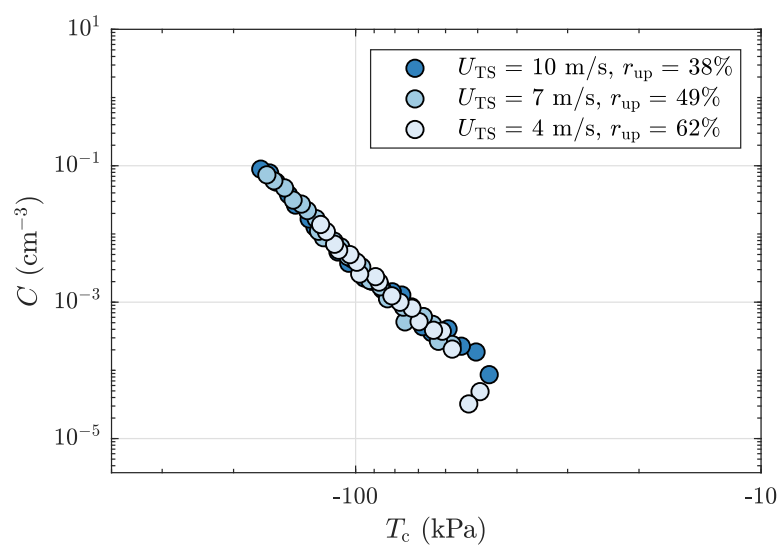

Fig. 12: Effect of test-section velocity, $U_{\mathrm{TS}}$, on the natural nuclei population. The relative saturation level of oxygen in the plenum, $r_{\text {up }}$, is also provided. There is little influence across a range of test conditions. Tunnel conditions were $\gamma=38-39 \%$ and $p_{\mathrm{TS}}=50 \mathrm{kPa}$.

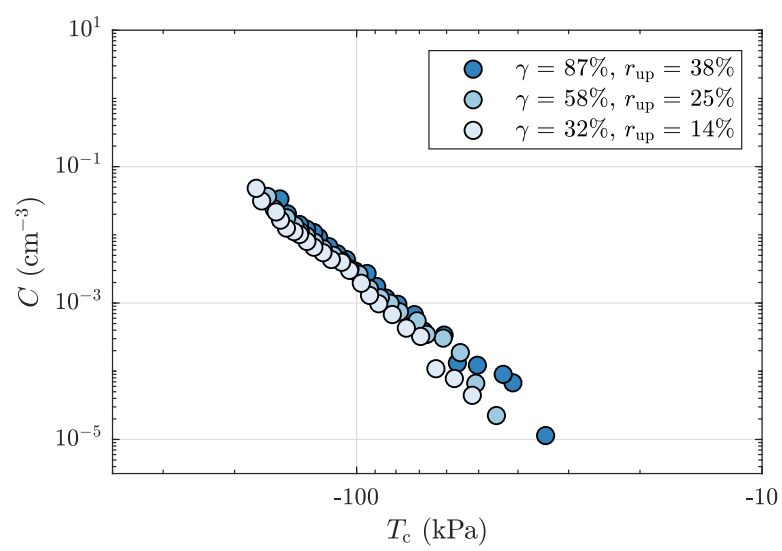

Fig. 13: Effect of dissolved oxygen content, $\gamma$, on the natural nuclei population. The relative saturation level of oxygen in the plenum, $r_{\text {up }}$, is also provided. There is little influence across a range of test conditions. Tunnel conditions were $p_{\mathrm{TS}}=200 \mathrm{kPa}$ and $U_{\mathrm{TS}}=7 \mathrm{~m} / \mathrm{s}$.

in the plenum $\left(r_{\text {up }}>100 \%\right)$, as shown in Fig. 14. This is not an unexpected result, as dissolved gas will tend to come out of solution when water is exposed to a pressure less than equilibrium saturation pressure.

A summary of nuclei distributions measured in the AMC tunnel presented as plenum static pressure against saturation pressure of water in the plenum is shown in Fig. 15. Each data point represents a measured nuclei distribution. It should be noted that while data in each of the Figs. 11 to 14 were taken over a maximum period of 12 hours to minimise historical effects, this was not practical for the large dataset captured in Fig. 15. Power-law trend lines were fitted to each nuclei distribution. Distributions that show a consistent power-law 


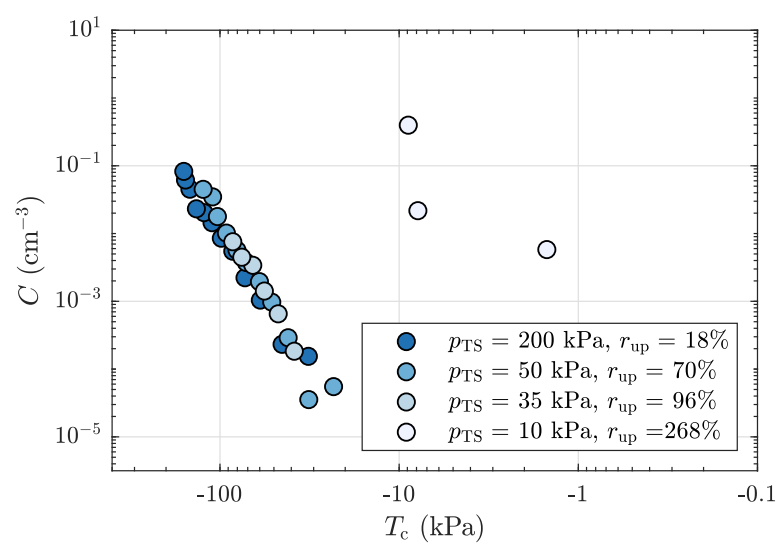

Fig. 14: Effect of test-section pressure, $p_{\mathrm{TS}}$, on the natural nuclei population at low test-section velocity. The relative saturation level of oxygen in the plenum, $r_{\text {up }}$, is also provided. The nuclei population increases noticeably when the test-section pressure is reduced to $10 \mathrm{kPa}$ (oversaturated). Tunnel conditions were $\gamma=38 \%$ and $U_{\mathrm{TS}}=2 \mathrm{~m} / \mathrm{s}$.

trend indicating no effect of increasing relative saturation are represented with hollow symbols. These indicate that the distributions were essentially unchanged from those presented in Figs. 11 to 13, hereafter termed the baseline. Distributions that depart from the power law as determined from the fitted parameters are represented with solid symbols. These signify that the nuclei distribution had increased above the baseline. The $10 \mathrm{kPa}$ data series in Fig. 14, as indicated by the solid red symbol in Fig. 15, is an example of this behaviour.

The red dashed line in Fig. 15 represents the conditions for which the water in the plenum is saturated with DO (i.e. $p_{\text {up }}=p_{\text {sat }}, r_{\text {up }}=100 \%$ ). The water upstream of the contraction is undersaturated for points above this line and oversaturated for points below. The natural nuclei population was observed to increase only for oversaturated conditions. Little information is available on the nature of the natural nuclei population, however, this similarity in behaviour to microbubbles indicates that gaseous diffusion plays a role in the population dynamics. Some nuclei distributions measured with oversaturated water remain at the baseline. In this sense, this behaviour could be attributed to the effect of surface tension delaying diffusion beyond equilibrium conditions, as occurs for microbubbles. An additional influence may stem from the dissolution of the free gas in the CSM circuit between the sampling probe and the venturi.

The increase in static pressure in the CSM circuit due to the decrease in dynamic pressure (relative to the test section) would make the water more under-

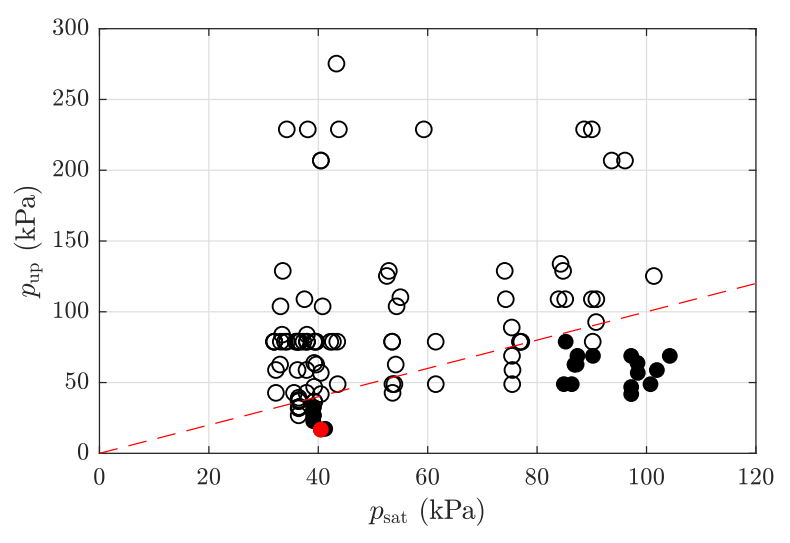

Fig. 15: Baseline natural nuclei populations (hollow) and distributions above the baseline (solid) as a function of plenum pressure, $p_{\text {up }}$, and saturation pressure of the water, $p_{\text {sat }}$. The red line represents when these pressures are equal ( $p_{\text {up }}=p_{\text {sat }}, r_{\text {up }}=100 \%$ ), i.e. the line represents a conservative delineation where populations remain at baseline if $r_{\text {up }}<100 \%$. The red dot represents the $10 \mathrm{kPa}$ data in Fig. 14 which is above the baseline.

saturated. This would result in the dissolution of free gas present, the extent of which is influenced by the residence time of the water in the CSM circuit as it transits between the sampling point and the centrebody venturi (approximately $5 \mathrm{~s}$ at the AMC tunnel). This effect could be reduced by moving the venturi closer to the test section and minimising the transit time at the expense of moving the range of measurable tensions towards higher tensions (i.e. more negative, according to the definition of tension in this paper).

\subsection{Effect of sampling location}

The historical trends discussed in the previous section necessitate regular monitoring of the natural nuclei population when carrying out low cavitation number testing in unseeded flows. Due to the relative size and positioning of the CSM sampling probe within the AMC tunnel test section, it is not ideal to sample water from the test section for CSM measurements while conducting cavitation testing. If the sampling probe was positioned upstream of a test component, it would affect the oncoming flow field. Additionally, it cannot always be positioned downstream due to the cavitating wake of the test model.

Tests were conducted to determine whether the natural nuclei population in the test-section water could be inferred from water sampled from the tunnel resorber. The CSM circuit can be configured to sample water 
from either the test section or the resorber in the lower limb of the tunnel (see Fig. 2). Measurements were repeated at the same nominal test-section conditions for both sampling locations. For undersaturated conditions in the plenum, no significant difference was observed regardless of whether the water was sampled from the test section or resorber, as shown in Fig. 16. This indicates stability of the natural population around the circuit. However, for water sampled from the test section in oversaturated conditions, the natural nuclei population tends to increase above the baseline with the amount of oversaturation, consistent with Fig. 15. This is also the case for higher test-section velocities (not shown). The natural nuclei populations of water sampled from the resorber, which had not been exposed to oversaturated conditions in the plenum, remained at the baseline even at extreme conditions (i.e. low $p_{\mathrm{TS}}$ and $U_{\mathrm{TS}}$, high $r_{\mathrm{up}}$ ). From these results it can be concluded that a baseline nuclei distribution in the test section can be inferred from CSM measurements of water sampled from the resorber for undersaturated conditions in the plenum (i.e. $\left.p_{\text {up }}>p_{\text {sat }}\right)$.

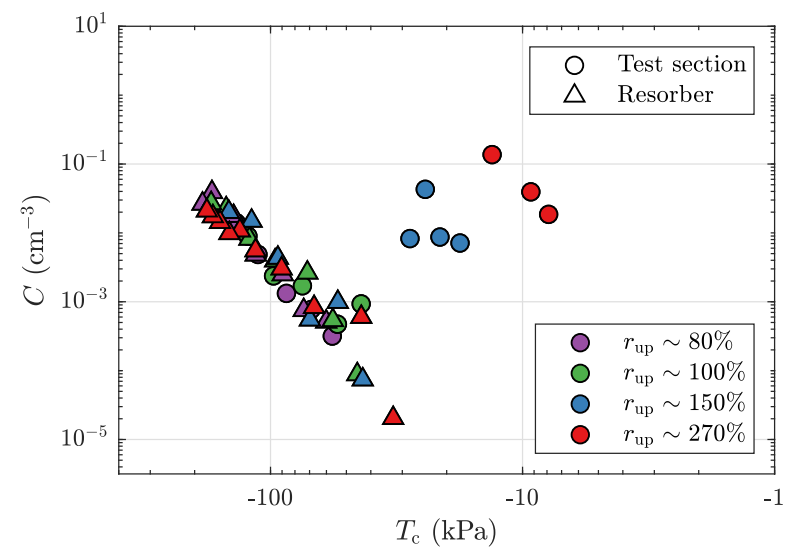

Fig. 16: Effect of sampling location on natural nuclei population for a range of relative saturation levels. The sampling location is denoted by the symbol shape. Measurements are at the baseline level for each location except for the test section when $r_{\text {up }}>100 \%$. Tunnel conditions were $\gamma=35-42 \%$ and $U_{\mathrm{TS}}=2 \mathrm{~m} / \mathrm{s}$.

\subsection{Comparisons with the ATLA test facility}

A comparison of measurements using the AMC CSM at the AMC and ATLA tunnels for similar operating conditions for a range of test-section velocities is shown in Fig. 17. The test-section pressure was approximately equal to the saturation pressure. The independence of the natural nuclei population from the test-section velocity at these conditions is consistent between the test facilities. The AMC tunnel data show a temporal variation of up to an order of magnitude as described above and the ATLA tunnel data lie within this range. For similar tunnel operating conditions, the AMC and ATLA tunnel data compare closely in magnitude which is somewhat coincidental. However, the close comparison of slope and independence of velocity indicate a universality of this water property.

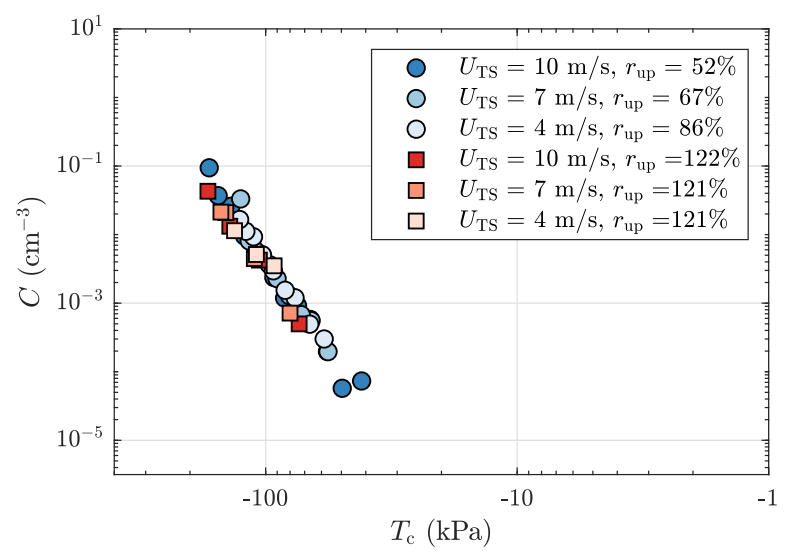

Fig. 17: Comparison of natural nuclei populations at the same nominal test conditions (across a range of test-section velocities, $U_{\mathrm{TS}}$, in the AMC (circles) and ATLA (squares) cavitation tunnels. The relative saturation levels of oxygen in the plenum, $r_{\text {up }}$, and the test section, $r_{\mathrm{TS}}$, are provided for each tunnel respectively. Similar distributions are observed from the two facilities of significantly differing circuit architecture and dimensions. Tunnel conditions were $\gamma=52-59 \%$ and $p_{\mathrm{TS}}=50 \mathrm{kPa}$.

At certain oversaturated conditions, an initial increase in the natural nuclei population followed by a reduction with decreasing throat pressure was observed in the ATLA FNS (Fig. 18). Since CSM nuclei population measurements are inherently cumulative, these results raise questions about the CSM behaviour. Simultaneous CSM and optical measurements could be used to confirm how representative these CSM nuclei distribution measurements are of the test-section water, however this would only be possible for a limited range of microbubble sizes due to the diffraction limits of optical techniques, see Fig. 1. The fact that the measured distributions seem to return to the baseline level at higher tensions tends to indicate the influence of another factor. This discrepancy only occurs when the flow rate through the venturi is low, which could indicate Reynolds number effects such as laminar boundary layer separation and cavity detachment as observed in a venturi tube diffuser by d'Agostino and Acosta (1991). 
The Reynolds numbers used for the venturi throat pressure calibration appear to be sufficiently high to ensure turbulent boundary layers (thus suppressing boundary layer separation in the diffuser section) in the singlephase flow (Khoo et al., 2016). However, it is more difficult to be sure of the boundary layer condition in two-phase flows in which instabilities may arise due to interactions between cavities and boundary layers. Furthermore, the venturi was operated at a slightly lower Reynolds number $\left(4.8 \times 10^{4}\right.$ for $\left.p_{\mathrm{TS}}=30 \mathrm{kPa}\right)$ in the ATLA FNS compared to the AMC tunnel $\left(5.9 \times 10^{4}\right)$, noting that the initial increase was not observed in the AMC cavitation tunnel under similar operating conditions. Alternatively, the behaviour may be related to the test facility or CSM circuit.

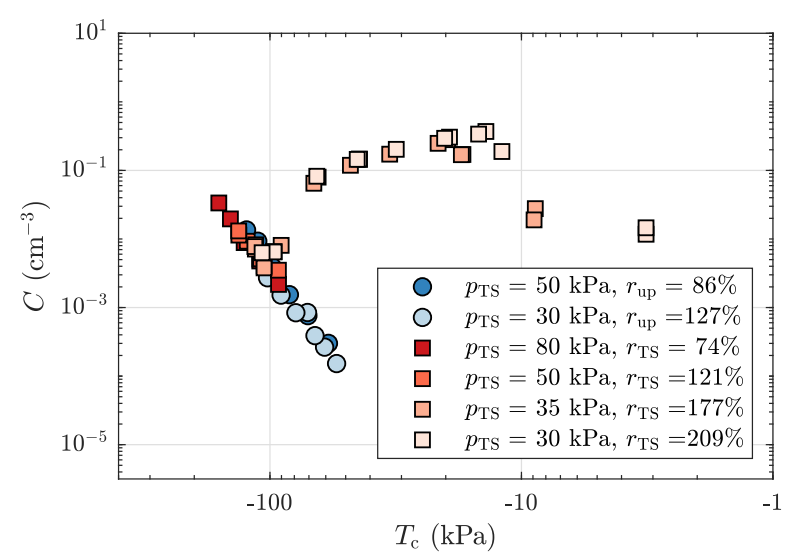

Fig. 18: Anomalous behaviour in the measured distribution was observed at the ATLA FNS (squares, at test-section pressures of $p_{\mathrm{TS}}=30 \mathrm{kPa} \& 35 \mathrm{kPa}$ ) but not at the AMC cavitation tunnel (circles). The relative saturation levels of oxygen in the test section, $r_{\mathrm{TS}}$, and the plenum, $r_{\text {up }}$, are provided for each tunnel respectively. Tunnel conditions were $U_{\mathrm{TS}}=4 \mathrm{~m} / \mathrm{s}$ and $\gamma=50-58 \%$.

For the ATLA FNS, the natural nuclei population appears to be controlled by the test-section relative saturation conditions, rather than the plenum. The variation of natural nuclei population with plenum static pressure and water saturation pressure is shown in Fig. 19, similar to the results presented in Fig. 15 for the AMC tunnel. The red dashed line represents where the plenum pressure equals the equilibrium saturation pressure (i.e. $\left.p_{\text {up }}=p_{\text {sat }}\right)$. The water in the plenum is undersaturated for points above this line and oversaturated for points below. Some of the solid points are located above this line which suggests that the saturation condition in the plenum at the ATLA FNS is not a suitable indicator of the natural nuclei population as it is for the AMC tunnel.

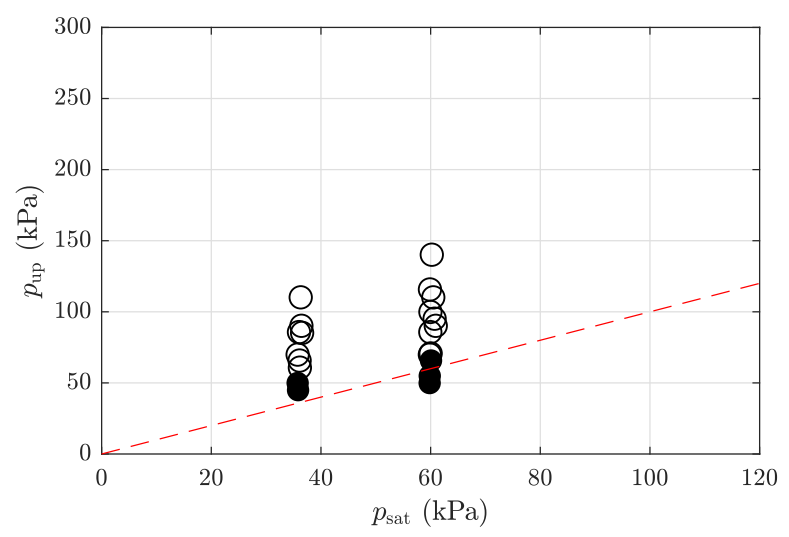

Fig. 19: Parameter map of all nuclei distributions measured at the ATLA FNS presented as upstream pressure (in the plenum), $p_{\text {up }}$, against saturation pressure, $p_{\text {sat }}$. The red line represents when these pressures are equal $\left(r_{\text {up }}=100 \%\right)$. Nuclei distributions at the baseline (hollow) and above the baseline (solid) are differentiated, but for this facility, the criterion $r_{\text {up }}<100 \%$ (as applicable to the AMC tunnel, see Fig. 15) is not a suitable measure of whether the population departs from the baseline.

If the data presented in Fig. 19 are replotted to consider how the nuclei population varies with test-section static pressure instead of plenum static pressure, then all solid symbols now remain below the red line as shown in Fig. 20. The natural nuclei population was observed to increase only for oversaturated conditions in the test section at this test facility. This suggests that the saturation condition in the test section is a more accurate indicator of the threshold for natural nuclei population variation in the ATLA FNS than the plenum conditions. This may be due to the water spending longer time in the FNS test section exposed to oversaturated conditions $(\mathcal{O}(1) \mathrm{s})$ than the AMC test section $(\mathcal{O}(100) \mathrm{ms})$, as discussed earlier. Furthermore, nuclei recirculation in the ATLA FNS, which has a lower limb with resorbing capability but not a downstream tank, unlike the AMC tunnel, could potentially add to the complexity of the observed behaviour. An investigation of the effectiveness of free gas removal in the ATLA FNS, similar to that shown in Sect. 3.2 for the AMC tunnel, is warranted. Some of the baseline distributions appear in the oversaturated region, as was observed for the AMC cavitation tunnel data in Fig. 15. It should also be noted that the ATLA FNS datasets with 'local peak' behaviour shown in Fig. 18 are categorised as be- 
ing above the baseline, although they appear to return to the baseline level at more negative tensions. Therefore, Fig. 20 should be interpreted with caution until the 'local peak' behaviour is better understood.

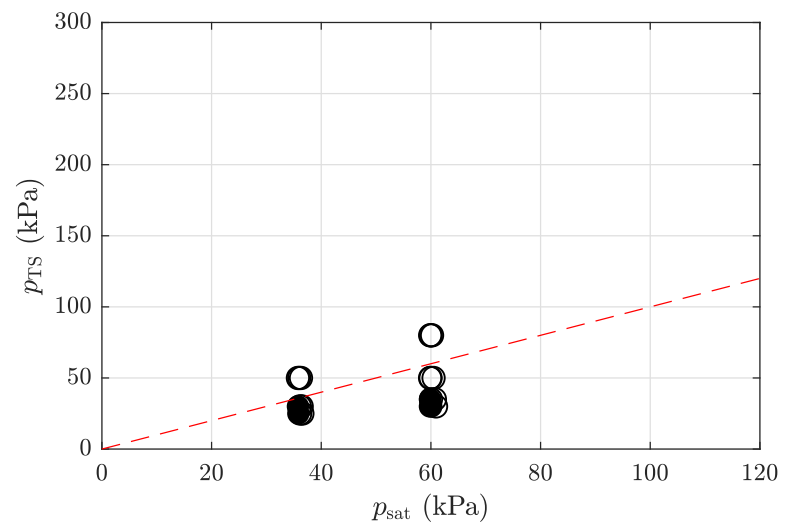

Fig. 20: Baseline natural nuclei populations (hollow) and distributions above the baseline (solid) measured at the ATLA FNS presented as a function of test-section pressure, $p_{\mathrm{TS}}$, and saturation pressure of the water, $p_{\text {sat }}$. The red line represents when these pressures are equal $\left(r_{\mathrm{TS}}=100 \%\right)$ and provides a conservative delineation above which (i.e. if $r_{\mathrm{TS}}>100 \%$ ) the population no longer remains at the baseline.

\subsection{Comparisons with other test facilities}

Given the similarity between nuclei populations measured in the AMC and ATLA tunnels, albeit with the same device, it raises the obvious question of how much similarity there is between facilities generally. A comparison of natural populations measured using a CSM in several cavitation tunnels all with water DO contents of about $30 \%$ is shown Fig. 21. A baseline natural nuclei population in the AMC cavitation tunnel is compared with the FNS in Japan (measured using the ATLA CSM) (Nagaya et al., 2011; Takahashi et al., 2019), Grand Tunnel Hydrodynamique (GTH) in France (Gindroz, 1995a), CEIMM cavitation tunnel in Italy (Gindroz, 1995a) and the University of Michigan (UM) 9inch water tunnel in the USA (Chang et al., 2009). With the exception of the Japanese data for which the same CSM device was used, each distribution was measured using a different CSM device and associated signal processing procedure. While the flow rate calibration of each venturi (and hence the pressure calibration of each venturi throat) is thought to be reliable, there are potential differences between discriminator algorithms employed with each device. Validation of CSM discriminators is a challenging task, which is reflected by the paucity of information in the open literature. These data show variations in concentration over some two orders of magnitude, however this is not a definitive comparison as many factors relating to CSM setup and operation, as well as facility operating history, are unknown. However, these data do show global similarity in terms of the power-law index and concentrations are generally within the range of variation observed over the longer term in the AMC tunnel, as discussed further below. On this basis, these results suggest a universal character of natural nuclei populations in conditioned cavitation tunnel water. To eliminate the differences in CSM setups, a standard device, and discriminator could be used to test natural nuclei populations in different facilities. This would allow comparisons to be made with greater confidence, at least in relative terms. Ultimately an optical device that counts every activation and eliminates any potential acoustic discriminator ambiguities or errors could be developed.

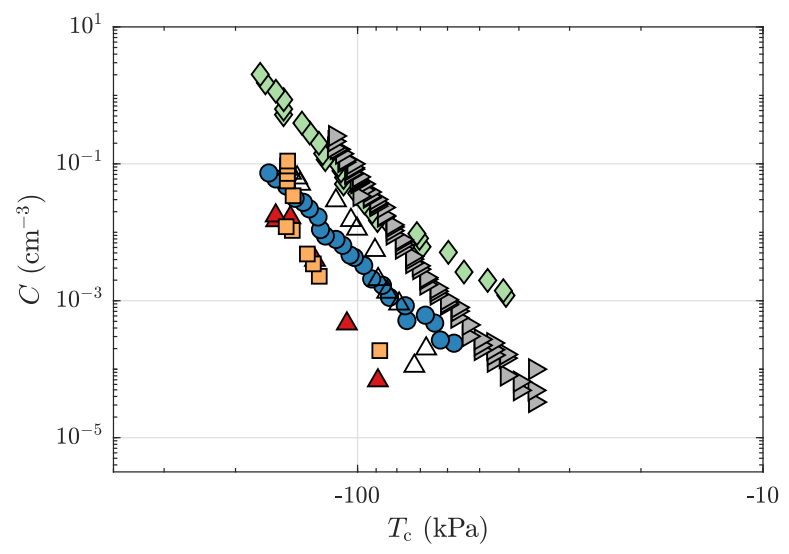

\footnotetext{
O AMC cavitation tunnel, Australia (Present study)

$\triangle \quad$ FNS, Japan (Takahashi et al., 2019)

$\triangle$ FNS, Japan (Nagaya et al., 2011)

$\square \quad$ GTH, France (Gindroz, 1995a)

$\diamond \quad$ CEIMM cavitation tunnel, Italy (Gindroz, 1995a)

$\triangleright$ UM 9-inch water tunnel $\gamma=25 \%$, USA (Chang et al., 2009)
}

Fig. 21: Baseline natural nuclei population comparison for a range of test facilities as measured using different CSM devices. The data show quite reasonable agreement between the different facilities noting the substantial variation in architecture and dimensions of the circuits and possible variation in the CSM design and/or signal processing techniques used. The dissolved oxygen content is nominally $30 \%$ of saturation at atmospheric pressure $(\gamma \sim 30 \%)$, unless otherwise specified. 
3.8 Comparisons with CSM measurements in environmental waters

Given the similarities between natural nuclei populations in different cavitation tunnels, it is of interest to also compare these with populations measured in environmental waters generally using a CSM. A comparison of the baseline population in the AMC tunnel with two measurements at two depths, taken in the Iroise Sea (Gindroz et al., 1995b) and in Lake Pend Oreille (Gowing and Shen, 2001), are shown in Fig. 22. For both these studies measurements were taken at a range of depths showing increasing critical tension with increasing depth. Two sample depths that bracket the range are shown in Fig. 22 to demonstrate the trend. Whilst the shallow depth measurements show some similarity in absolute terms, they have significantly different slopes. The populations at deeper depths differ significantly with the ocean data at $60 \mathrm{~m}$ depth (Gindroz et al., 1995b) spanning more negative tensions than the lake data at $50 \mathrm{~m}$ depth (Gowing and Shen, 2001) (not shown) which sits between the 10 and $100 \mathrm{~m}$ datasets shown in Fig. 22. The deep measurements in the lake show close comparison with the AMC tunnel baseline measurement. The measurements taken in the ocean at both depths show a much greater slope than the lake and AMC baseline measurements implying a narrow range of nuclei critical tensions.

The ocean measurements by Gindroz et al. (1995b) are taken with a similar experimental setup as used for the natural population taken in the French GTH shown in Fig. 21 which also shows a greater slope which could indicate device-specific results. Although the data are not plotted together, the GTH natural population does not compare well with the deep population measured in the Iroise Sea. Given the limited data available from CSM measurements, and differences in devices, in environmental waters it is difficult to comment on how well these populations compare with those measured in test facilities other than to conclude that they are of similar orders of magnitude in terms of critical tensions and concentrations. As with the comparison of measurements in facilities, measurements using a definitive technique or at least a consistent technique are required to gain greater insight.

3.9 Quantitative variations in measured populations and comparison with other experiments and theories

Extensive measurements of nuclei and microbubble populations in laboratory water, and environmental waters, have been made using a range of optical and acoustic techniques and it is of interest to compare these with

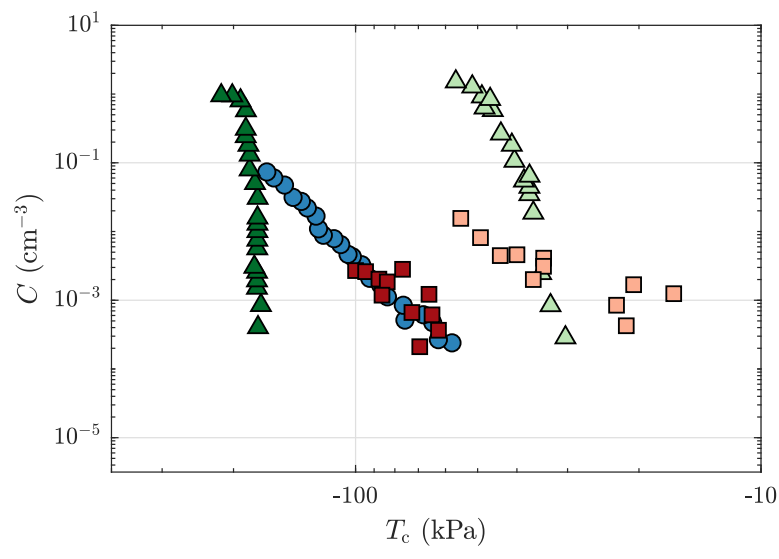

$\begin{array}{ll}\bigcirc & \text { AMC cavitation tunnel, Australia (Present study) } \\ \triangle & \text { Iroise Sea } 5 \mathrm{~m} \text { (Gindroz et al., 1995b) } \\ \Delta & \text { Iroise Sea } 60 \mathrm{~m} \text { (Gindroz et al., 1995b) } \\ \square & \text { Lake Pend Oreille 10m (Gowing and Shen, 2001) } \\ \square & \text { Lake Pend Oreille 100m (Gowing and Shen, 2001) }\end{array}$

Fig. 22: Comparison of nuclei distributions in a laboratory and in environmental waters of varying depth as measured using CSM devices. The AMC tunnel data compare closely to the lake measurement at a depth of $100 \mathrm{~m}$.

the AMC tunnel natural population. A comparison of baseline AMC tunnel populations taken over two years and a single long sample taken over 40 hours (Venning et al., 2018) are compared with a diversity of measurements using several techniques, as shown in Fig. 23. One population measured using a Coulter counter (an electromagnetic technique) is also included for comparison. It should be noted that microbubble or nuclei distributions can be represented in four ways, either as cumulative or non-cumulative concentration and either as a function of critical tension (or critical diameter) or equivalent bubble diameter at a particular reference pressure, $p_{\infty}$. All AMC populations measured using the CSM presented in Fig. 23 have been converted to noncumulative concentration as a function of equivalent bubble diameter, $d$, at ambient pressure, $p_{\infty}$. This diameter can be calculated numerically from the critical pressure by rearranging Eq. 1 as:

$\left(p_{\infty}-p_{\mathrm{v}}\right)\left(\frac{d}{4 S}\right)^{3}+\left(\frac{d}{4 S}\right)^{2}=\frac{4}{27\left(p_{\mathrm{v}}-p_{\mathrm{c}}\right)^{2}}$

where $p_{\infty}=p_{\mathrm{TS}}$ for AMC tunnel measurements. For the purposes of quantitative comparison all distributions can be represented as a power law:

$\frac{\partial C}{\partial d}=A d^{n}$

where $A$ is the constant of proportionality and $n$ is the power-law index. 
All AMC baseline natural nuclei measurements show a concentration variation of between one and two orders of magnitude for a fixed diameter or less than one order of magnitude in diameter for a fixed concentration. Least-squares regression analysis of the two years of population measurements reveal $n$, the index of the power law, to average about -6.2 with high probability but to vary overall between -3.4 and -12.9 . The multiplier $A$ similarly averages about $9.8 \times 10^{8}$ with high probability but varies between $4.6 \times 10^{7}$ to $4.3 \times 10^{9}$. Within the spread of these parameters there is no clear correlation with any tunnel operating parameters (DO, velocity or pressure) nor any long-term temporal fluctuations. The long data measurement by Venning et al. (2018) lies at about the mean of this range. Whilst this variation in global terms may be considered to be relatively small, for precise measurements of cavitation inception this range may be considered large necessitating regular measurement. Although the results presented do suggest that only one point may need to be measured to establish the entire distribution if it is assumed that the power-law index remains nominally unchanged for undersaturated conditions as defined above.

The populations measured using optical or acoustic techniques show some overlap in size with the AMC CSM populations but are generally two to three orders of magnitude greater in size but comparable in concentration range. Most of the populations are within the 10 to $100 \mu \mathrm{m}$ size range which is typically the range for modelling nucleation in relatively high cavitation number flows, as noted in the introduction. There are several factors that should be noted. Most of the measurements made with optical or acoustic techniques are in water nominally saturated with air at atmospheric pressure although there are some tunnel populations where the water is degassed. The optical techniques could register not only bubbles but also impurities potentially artificially increasing concentrations. On the other hand, acoustic techniques should only respond to bubble dynamics. It can also be observed in Fig. 23 that the older ocean nuclei measurements are comparable with more recent laser diffraction measurements by Randolph et al. (2014). They also observed that the power-law index shows little variation over short time scales, but varies significantly between days, i.e. about -4.2 on one day and -6.0 on another. Overall, most of the populations measured using optical and acoustic techniques in facility and environmental waters compare reasonably closely implying universal behaviour.

Of all the populations measured using these techniques, it is only those by Shen et al. (1984) and in particular by Gavrilov (1969) that show reduced concentrations/sizes demonstrating the effects of degassing and standing over long periods respectively. Other populations measured by Arndt and Keller (1976) and Keller and Weitendorf (1976) show similar trends with reducing dissolved gas content but with initially higher concentrations and larger sizes. These differences could be attributable to factors such as residence and circuit pressure history, which are influenced by the tunnel architecture, that affect the life and existence of entrained bubbles. The data overall tend to follow a power law with an index of about -4 as can be seen from the solid, thin, grey lines with this slope shown on Fig. 23, which come from the phenomenological model of Franklin (1992) discussed below.

Finally, as noted above, only limited information can be gained on the nature of natural nuclei populations from these results. However, comparisons with other results and theories can perhaps provide some additional insight into such complex and apparently unpredictable phenomena. Apart from the long sample AMC tunnel natural population from Venning et al. (2018), all baseline data lie within the size range decade of 0.5 to $5 \mathrm{\mu m}$ equivalent bubble diameter. This size range corresponds with stabilised microbubble sizes in seawater found by Johnson and Cooke (1981). They report that 40 to $100 \mu \mathrm{m}$ diameter microbubbles generated in slightly degassed seawater under controlled conditions would either quickly completely dissolve while others would reduce to finite sizes apparently stabilised by films compressed during dissolution. These stabilised bubbles ranged in sizes between 1 and $13 \mu \mathrm{m}$ diameter. They also report that application of pressure reduction would grow some bubbles and that they would return to original sizes if the initial pressure was restored, or that with extended pressure increase some would dissolve completely. This behaviour could explain the variation in tunnel natural nuclei populations after tunnel operations involving large populations of bubbles such as filling and emptying, or degassing, as well as the effects of time, pressure and dissolved gas content.

Beyond possible explanations for microbubble evolution from large sizes there is also the possibility of growth from small sizes or homogeneous nucleation. As noted earlier, Franklin $(1992,1994)$ proposed a powerlaw model based on arguments of self similarity and that the population could be limited to a finite minimum size attributable to homogeneous nucleation based on dissolved gas content. Franklin argued how the effect of dissolved gas and standing time may affect the minimum number of molecules (numbered at the top of Fig. 23) required to form the smallest sustainable cluster of free gas. This model is shown for comparison in Fig. 23, where the dissolved air concentration is calculated assuming saturation at atmospheric conditions 
for each of the distributions shown. Ward et al. (1970) showed how dissolved gas affected the minimum sustainable nucleus size and how this was smaller for higher gas contents. That is, fewer molecules are required to form a nucleus for higher dissolved gas contents. This work on the effects of dissolved gas on homogeneous nucleation theory has been extended by Kwak and Oh (2004) and Němec (2016). Unfortunately this theory has not been extended to more practical liquids and to nuclei size distributions but may provide potential guidance in developing future investigations.

\section{Conclusions}

The natural nuclei population dynamics within the cavitation tunnel at the Australian Maritime College (AMC) Cavitation Research Laboratory have been characterised using a Cavitation Susceptibility Meter (CSM). This population follows a power law and remains invariant at a baseline level over short time scales. That is, provided the water remains undersaturated in the low pressure part of the tunnel circuit upstream of the test section (plenum). For this undersaturated condition, the population also remains invariant throughout the tunnel circuit such that it can be measured from any location. However, at extreme operating conditions, the population can increase when the water is oversaturated. This indicates that this condition should be avoided unless direct measurements are concurrently made. Although little information is available on the nature of this population, it exhibits similar behaviour to microbubbles, suggesting gaseous diffusion plays a role in the population dynamics. The population was observed to decrease by approximately an order or magnitude during a week-long test campaign and to fluctuate by a similar amount over longer time scales. These historical trends necessitate regular monitoring of the population when investigating low cavitation number flows in which natural nuclei are active.

Natural nuclei populations were also measured in the Japanese Acquisition, Technology \& Logistics Agency (ATLA) Flow Noise Simulator (FNS) using the AMC CSM. Measured populations were found to compare closely for undersaturated conditions suggesting a universal characteristic. However, the reference location in the ATLA FNS at which the pressure may be used to threshold whether the water is under or oversaturated was not found to be the plenum, unlike for the AMC tunnel. The pressure in the FNS test section, in which high flow velocity occurs, appears to be a more suitable indicator. While the AMC tunnel features a downstream tank (and large resorber) for free gas removal, such a tank is not part of the ATLA FNS architecture, which may lead to the recirculation of nuclei. The differences in natural nuclei population dynamics observed between the two facilities may, at least partially, be attributed to differences in tunnel design.

Measurements of natural populations in several tunnels of varying circuit architecture and volume using different CSMs show similar behaviour further suggesting the possibility of a universal characteristic. To confirm this possibility, at least in a relative sense, measurements would need to be taken in different facilities with the same CSM. Alternatively, newer technology such as an optical-based CSM that would eliminate acoustic ambiguities (yet still allow small nuclei to be measured) needs to be developed.

Comparison of CSM measurements, using different devices in test facilities and environmental waters show similar populations in a general sense. However, this observation is based on few measurements demonstrating the need for more data to be acquired and preferably, as noted above, with newer CSM technologies.

Microbubble or nuclei measurements in environmental waters using optical or acoustic techniques show populations in the 10 to $100 \mu \mathrm{m}$ diameter range, as typically modelled for cavitation nucleation. However, CSM data show that smaller size populations, in the 0.5 to $5 \mathrm{\mu m}$ equivalent bubble diameter range, as measured in facilities are also present in the these waters.

To gain further insight into the nature of these nuclei populations, including whether they can form from stabilisation of dissolving larger bubbles or from smaller homogeneous nuclei, simpler experiments eliminating many of the variables that apparently affect the populations in practical water volumes are required.

Acknowledgements The authors acknowledge the support of the University of Tasmania, the Defence Science and Technology Group and the Acquisition, Technology \& Logistics Agency. The authors thank AMC technical officers, Mr Robert Wrigley and Mr Steven Kent, and ATLA technical officer, Mr Kenji Naganuma, for providing technical assistance with test facility configuration and operation as well as CSM hardware configuration. 


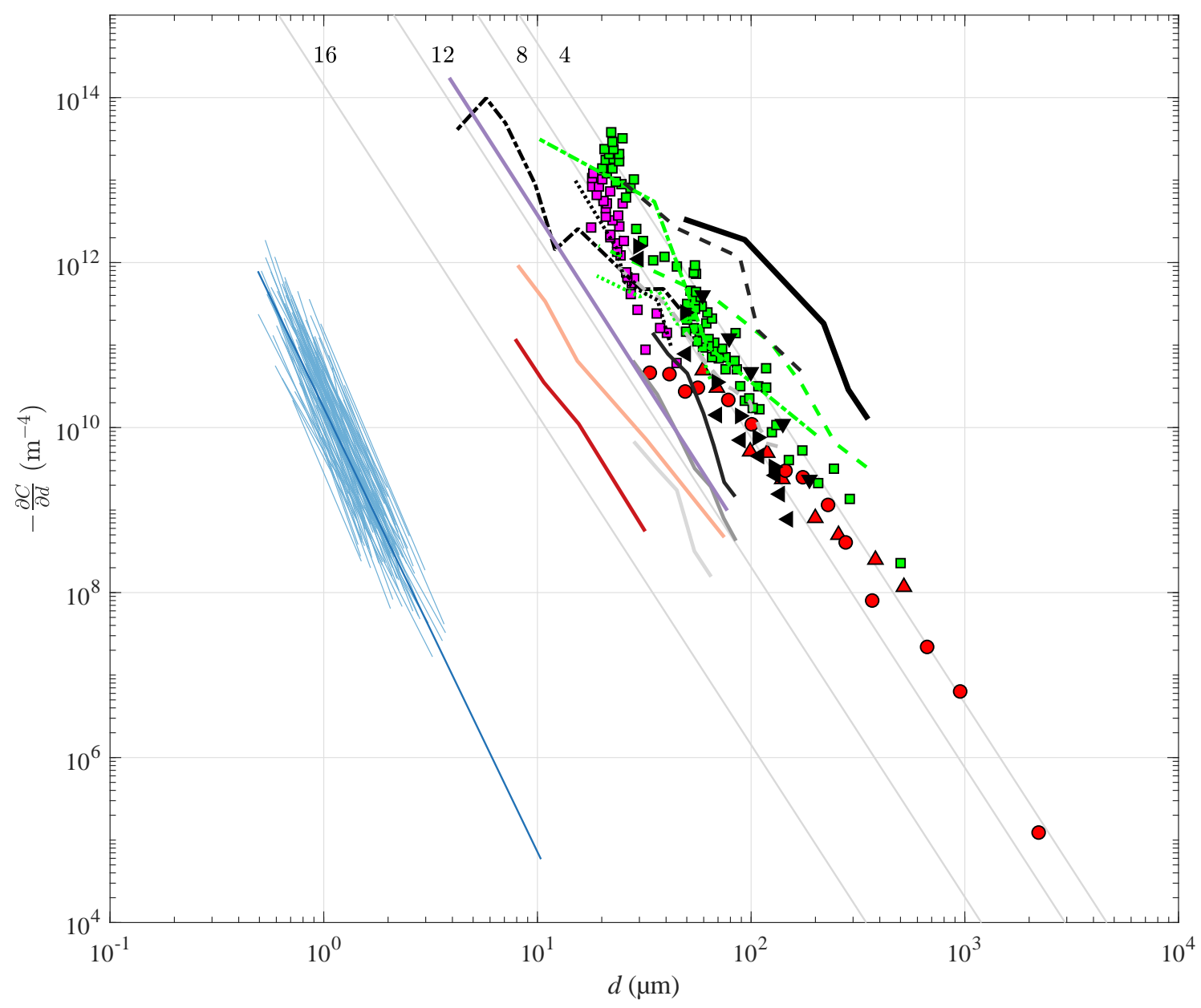

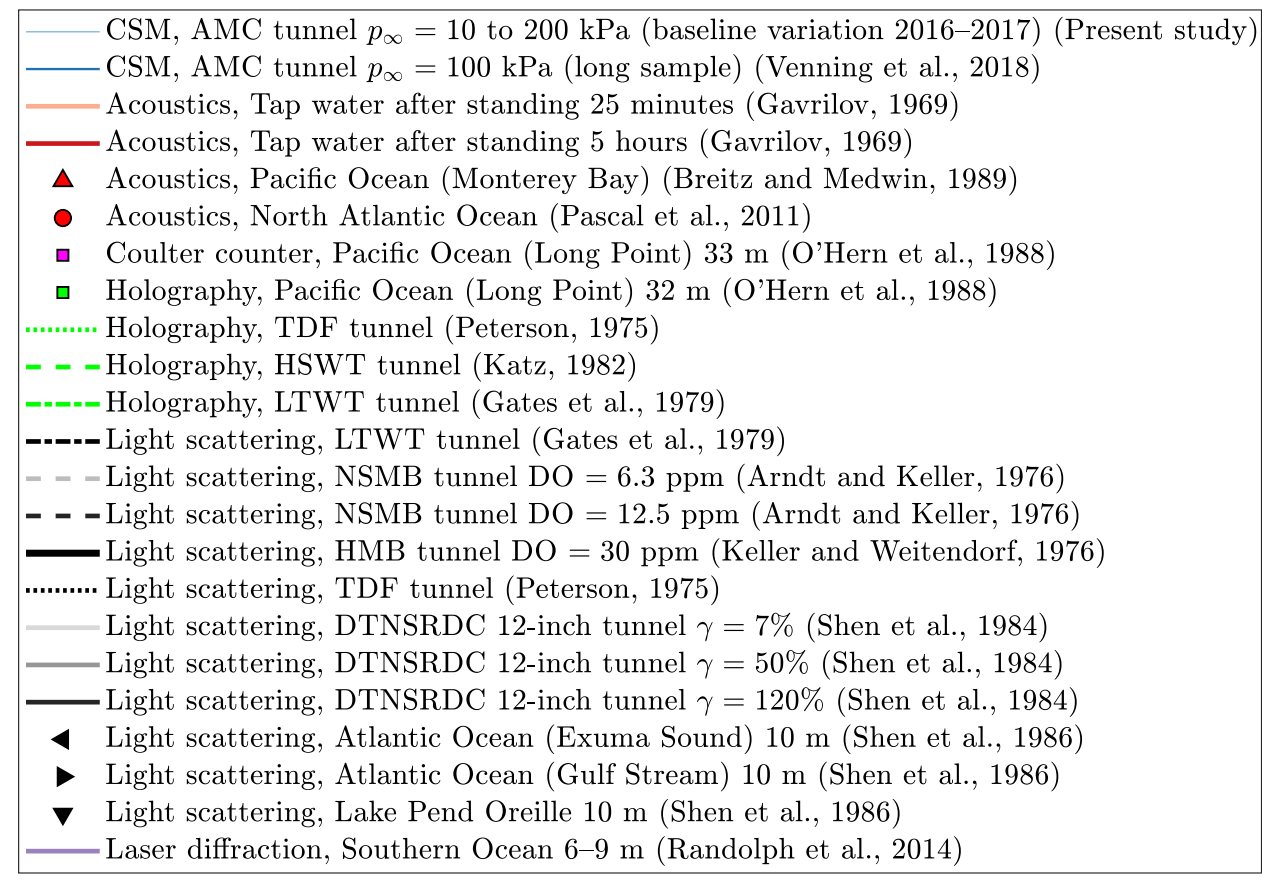

Fig. 23: Comparison of nuclei distribution histograms from laboratory and environmental waters for a variety of measurement techniques. $-\frac{\partial C}{\partial d}$ is the derivative of the cumulative histogram and is equivalent to the number density distribution function in Katz (1982); Gates et al. (1979). $d$ is the nucleus diameter at ambient pressure, $p_{\infty}$. The solid, thin, grey lines come from the phenomenological model of Franklin (1992), with the numbers at the top of the figure representing the minimum number of molecules required to form the smallest sustainable cluster of free gas. The AMC data series are based on fits to cumulative histogram CSM data. Note that the holographic and light scattering methods may detect solid, non-cavitating particles, which may result in the overestimation of nuclei concentrations. 


\section{References}

Arndt R, Keller A (1976) Free gas content effects on cavitation inception and noise in a free shear flow. In: Two phase flow and cavitation in power generation systems. Grenoble, 30 March-2 April 1976

Atlar M (2002) The specialist committee on water quality and cavitation - final report. Proc 23rd ITTC 2

Billet M (1984) Cavitation nuclei measurements. In: ASME Int Symp on Cavitation Inception, New Orleans, LA

Billet ML (1985) Cavitation nuclei measurements-a review. In: Cavitation and Multiphase Flow Forum

Brandner P (2018) Microbubbles and cavitation: Microscales to macroscales. In: 10th Int Cavitation Symp (CAV2018)

Brandner P, Lecoffre Y, Walker G (2007) Design considerations in the development of a modern cavitation tunnel. In: 16th Australasian Fluid Mechanics Conf

Brandner PA, Venning JA, Pearce BW (2018) Wavelet analysis techniques in cavitating flows. Philosophical Transactions of the Royal Society A: Mathematical, Physical and Engineering Sciences 376(2126):20170242

Breitz N, Medwin H (1989) Instrumentation for insitu acoustical measurements of bubble spectra under breaking waves. J Acoust Soc Am 86(2):739-743

Brennen CE (1994) Observations of cavitating flow. In: Proc 20th Symp on Naval Hydrodynamics, National Academy Press

Brennen CE (1995) Cavitation and Bubble Dynamics. Cambridge University Press

Chang N, Yakushiji R, Ganesh H, Ceccio S (2009) Mechanism and scalability of tip vortex cavitation suppression by water and polymer injection. In: Proc 7th Int Symp on Cavitation

d'Agostino L, Acosta A (1991) Separation and surface nuclei effects in a cavitation susceptibility meter. J Fluids Eng 113(4):695-698

Deane GB, Stokes MD (2002) Scale dependence of bubble creation mechanisms in breaking waves. Nature 418(6900):839

Fox FE, Herzfeld KF (1954) Gas bubbles with organic skin as cavitation nuclei. J Acoust Soc Am 26(6):984989

Franc JP, Michel JM (2006) Fundamentals of Cavitation, vol 76. Springer science \& Business media

Franklin R (1992) A note on the radius distribution function for microbubbles of gas in water. In: ASME Cavitation and Multiphase Flow Forum, vol 135, pp $77-85$

Franklin R (1994) The cavitating submerged jet. Tech. rep., American Society of Mechanical Engineers, New
York, NY (United States)

Garrett C, Li M, Farmer D (2000) The connection between bubble size spectra and energy dissipation rates in the upper ocean. J Phys Oceanogr 30(9):2163-2171

Gates E, Billet M, Katz J, Ooi K, Holl J (1979) Cavitation inception and nuclei distributions joint ARL/CIT experiments. Tech. rep., Pennsylvania Stat Univ University Park Applied Research Lab

Gavrilov L (1969) On the size distribution of gas bubbles in water. Sov Phys - Acoustics 15(1):22-24

Gindroz B (1995a) Propeller cavitation characteristics: The practical interest of nuclei measurements in test facilities and at sea. In: Proc ASME FED Symp on Cavitation

Gindroz B, Billard JY, Geistdoerfer P (1995b) Cavitation nuclei measurements at sea. ASMEPUBLICATIONS-HTD 321:497-504

Gindroz B, Bailo G, Matera F, Elefante M (1997) Influence of the cavitation nuclei on the cavitation bucket when predicting the full-scale behavior of a marine propeller. In: Proc 21st Symp on Naval Hydrodynamics, pp 839-850

Gowing S, Shen YT (2001) Nuclei effects on tip vortex cavitation scaling. In: 4th Int Symp on Cavitation, California

Gowing S, Vikram C, Burton S (1988) Comparison of holographic, light scattering and venturi techniques for bubble measurements in a water tunnel. In: ASME Cavitation and Multiphase Flow Forum, pp 25-28

Harvey EN, Barnes D, McElroy WD, Whiteley A, Pease D, Cooper K (1944) Bubble formation in animals. i. physical factors. J Cell Physiol 24(1):1-22

Johnson BD, Cooke RC (1981) Generation of stabilized microbubbles in seawater. Science 213(4504):209-211

Katz J (1982) Cavitation inception in separated flows. $\mathrm{PhD}$ thesis, California Institute of Technology

Keller A, Weitendorf E (1976) Influence of undissolved air content on cavitation phenomena at the propeller blades and on induced hull pressure amplitudes. In: Proc lAHR Symp on Two Phase Flow and Cavitation in Power Generation System, pp 65-76

Khoo M, Venning J, Pearce B, Brandner P, Lecoffre Y (2016) Development of a cavitation susceptibility meter for nuclei size distribution measurements. In: 20th Australasian Fluid Mechanics Conf.

Khoo M, Venning J, Takahashi K, Arai J, Mori T, Pearce B, Brandner P, Ranmuthugala D (2017) Joint research between Australia and Japan on the cavitation inception of marine propellers and control surfaces. In: MAST Asia 2017, pp 1-6 
Kwak HY, Oh SD (2004) Gas-vapor bubble nucleation - a unified approach. J Colloid Interface Sci 278(2):436-446

Liu Z, Sato K, Brennen CE (1993) Cavitation nuclei population dynamics in a water tunnel. In: ASME, American Society of Mechanical Engineers, 153, pp $119-124$

Mori T, Naganuma K, Kimoto R, Yakushiji R, Nagaya S (2007) Hydrodynamic and hydroacoustic characteristics of the Flow Noise Simulator. In: Proc 5th ASME-JSME Joint Fluids Eng Conf, FEDSM200737531

Nagaya S, Kimoto R, Naganuma K, Mori T (2011) Observation and scaling of tip vortex cavitation on elliptical hydrofoils. In: ASME-JSME-KSME 2011 Joint Fluids Eng Conf, American Society of Mechanical Engineers, pp 225-230

Němec T (2016) Homogeneous bubble nucleation in binary systems of liquid solvent and dissolved gas. J Chem Phys 467:26-37

Norris SJ, Brooks I, de Leeuw G, Sirevaag A, Leck C, Brooks B, Birch C, Tjernstrom M (2011) Measurements of bubble size spectra within leads in the arctic summer pack ice. Ocean Science

Pascal RW, Yelland MJ, Srokosz MA, Moat BI, Waugh EM, Comben DH, Cansdale AG, Hartman MC, Coles DG, Chang Hsueh P (2011) A spar buoy for highfrequency wave measurements and detection of wave breaking in the open ocean. J Atmospheric Ocean Technol 28(4):590-605

Peterson F, Danel F, Keller A, Lecoffre Y (1975) Comparative measurements of bubble and particulate spectra by three optical methods. Report of Cavitation Committee, 14th ITTC

Pham T, Michel J, Lecoffre Y (1997) Dynamical nuclei measurement: On the development and the performance evaluation of an optimized center-body meter. J Fluids Eng 119(4):744-751

Randolph K, Dierssen HM, Twardowski M, CifuentesLorenzen A, Zappa CJ (2014) Optical measurements of small deeply penetrating bubble populations generated by breaking waves in the Southern Ocean. J Geophys Res: Oceans 119(2):757-776

Russell P, Giosio D, Venning J, Pearce B, Brandner $\mathrm{P}$, Ceccio S (2018) Microbubble disperse flow about a lifting surface. In: 32nd Symp on Naval Hydrodynamics, Hamburg, Germany

Russell P, Venning J, Pearce B, Brandner P (2019) Calibration of Mie Scattering Imaging for microbubble measurement in hydrodynamic test facilities. Manuscript submitted for publication

Shen Y, Gowing S, Pierce R (1984) Cavitation susceptibility measurements by a venturi. In: ASME Int Symp on Cavitation Inception, New Orleans, LA

Shen YT, Gowing S, Eckstein B (1986) Cavitation susceptibility measurements of ocean lake and laboratory waters. Tech. rep., David W Taylor Naval Ship Research and Development Center Bethesda MD

Stramski D, Boss E, Bogucki D, Voss KJ (2004) The role of seawater constituents in light backscattering in the ocean. Prog Oceanogr 61(1):27-56

Takahashi K, Arai J, Mori T (2019) Nuclei population dynamics in NSRC/ATLA Flow Noise Simulator. Tech. rep., Acquisition, Technology \& Logistics Agency, Japan

Venning J, Khoo M, Pearce B, Brandner P (2018) Background nuclei measurements and implications for cavitation inception in hydrodynamic test facilities. Exp Fluids 59(4):71

Ward C, Balakrishnan A, Hooper F (1970) On the thermodynamics of nucleation in weak gas-liquid solutions. J Basic Eng 92(4):695-701

Warneck P, Williams J (2012) The atmospheric chemist's companion: Numerical data for use in the atmospheric sciences. Springer Science \& Business Media

Worch E (2015) Hydrochemistry: Basic Concepts and Exercises. Walter de Gruyter GmbH \& Co KG

Zhang X (2001) Influence of bubbles on the waterleaving reflectance. $\mathrm{PhD}$ thesis, Dalhousie University 